\title{
Using health technology assessment to assess the value of new medicines: results of a systematic review and expert consultation across eight European countries
}

\author{
Aris Angelis ${ }^{1} \cdot$ Ansgar Lange $^{1} \cdot$ Panos Kanavos $^{1}$
}

Received: 2 July 2016/ Accepted: 17 January 2017/Published online: 16 March 2017

(C) The Author(s) 2017. This article is published with open access at Springerlink.com

\begin{abstract}
Background Although health technology assessment (HTA) systems base their decision making process either on economic evaluations or comparative clinical benefit assessment, a central aim of recent approaches to value measurement, including value based assessment and pricing, points towards the incorporation of supplementary evidence and criteria that capture additional dimensions of value.

Objective To study the practices, processes and policies of value-assessment for new medicines across eight European countries and the role of HTA beyond economic evaluation and clinical benefit assessment.

Methods A systematic (peer review and grey) literature review was conducted using an analytical framework examining: (1) 'Responsibilities and structure of HTA agencies'; (2) 'Evidence and evaluation criteria considered in HTAs'; (3) 'Methods and techniques applied in HTAs'; and (4) 'Outcomes and implementation of HTAs'. Study countries were France, Germany, England, Sweden, Italy, Netherlands, Poland and Spain. Evidence from the literature was validated and updated through two rounds of feedback involving primary data collection from national experts.
\end{abstract}

Electronic supplementary material The online version of this article (doi:10.1007/s10198-017-0871-0) contains supplementary material, which is available to authorized users.

Panos Kanavos

p.g.kanavos@1se.ac.uk

1 Department of Social Policy and Medical Technology Research Group, LSE Health, London School of Economics and Political Science, Houghton Street, London WC2A 2AE, UK
Results All countries assess similar types of evidence; however, the specific criteria/endpoints used, their level of provision and requirement, and the way they are incorporated (e.g. explicitly vs. implicitly) varies across countries, with their relative importance remaining generally unknown. Incorporation of additional 'social value judgements' (beyond clinical benefit assessment) and economic evaluation could help explain heterogeneity in coverage recommendations and decision-making.

Conclusion More comprehensive and systematic assessment procedures characterised by increased transparency, in terms of selection of evaluation criteria, their importance and intensity of use, could lead to more rational evidencebased decision-making, possibly improving efficiency in resource allocation, while also raising public confidence and fairness.

Keywords Health technology assessment (HTA) - Value assessment - Innovative medicines · High cost medicines . Pharmaceutical policy · European Union · Systematic review $\cdot$ Expert consultation

JEL Classification I (Health, Education, and Welfare) · I1 (Health) · I10 (General) · I11 (Analysis of Health Care Markets) · I18 (Government Policy; Regulation; Public Health)

\section{Background}

Current value assessment and appraisal approaches of medical technologies using economic evaluation or adopting comparative clinical benefit assessment in order to inform coverage decisions and improve efficiency in resource allocation have been subject to criticism for a number of reasons. 
Most health technology assessment (HTA) systems base their decision-making process on cost per outcome metrics of economic evaluations such as, for example, the cost per quality adjusted life year (QALY) [1]. However a key limitation of the QALY approach is the inadequacy of capturing social value [2-4]. It is clear that a central aim of more recent approaches to value measurement, including value-based assessment and value-based pricing, involves the incorporation of additional parameters capturing other dimensions of value into the overall valuation scheme [5, 6]. Although a number of additional criteria beyond scientific value judgements are considered to assess the evidence submitted and inform coverage decisions in different HTA settings [7], their use remains implicit or ad hoc rather than explicit and systematic.

Another drawback is caused by the way in which value is assessed and appraised, often resulting in unexplained heterogeneity of coverage decisions across settings even for the same drug-indication pair [8-14]. Although some of this decision heterogeneity could be justified on the grounds of different budget constraints and national priorities, inconsistencies in medicines' eligibility for reimbursement across countries can give rise to an international 'post-code' lottery for patient access, even in the same geographical region and can have important implications for equity and fairness, especially when differences remain unexplained [11]. Several studies have acknowledged the need for well-defined decision-making processes that are fairer and more explicit [15-17]. By ensuring 'accountability for reasonableness' and providing a better understanding of the rationale behind decision-making, decisions will also have enhanced legitimacy and acceptability $[12,18]$.

By reviewing and synthesising the evidentiary requirements (both explicit and implicit), the methods and techniques applied and how they contribute to decision-making, the objective of this study is to provide a critical review of value assessment and appraisal methods for new medicines, including the evaluation criteria employed across a number of jurisdictions in Europe deploying explicit evaluation frameworks in their HTA processes. More specifically, the study seeks to determine whether HTA processes incorporate additional criteria beyond economic evaluation or clinical benefit assessment, and, if so, which ones and how they inform coverage recommendations. To date no study has provided a similar review and analysis of HTA policies and practices for innovative medicines across different European countries to this extent. In fulfilling the above aims, the next section outlines the methods and includes the components of the analytical framework adopted for this purpose; subsequently, the evidence collected from eight European countries is presented and discussed, before presenting the policy implications.

\section{Methods}

We outline and propose a conceptual framework to facilitate the systematic review of HTA processes and capture their salient features across settings following previous evidence [19]. Based on that, we collected the relevant evidence, relying on both primary and secondary sources. The evidence base covered eight EU Member States that have arms-length HTA agencies and recognised HTA processes. The study took place in the context of Advance-HTA, an EU-funded project aiming to contribute to advances in the methods and practices for HTA in Europe and elsewhere [20].

Secondary sources of evidence comprised a systematic review of the country-specific value-assessment peer review literature using an analytical framework to investigate the practices, processes and policies of value-assessment and their impact, as observed in the study countries.

Evidence from the literature was validated by means of two rounds of feedback involving primary data collection: the first was from Advance-HTA consortium partners [20], while the second involved a detailed validation of the study's results by national experts following the incorporation of all literature results and feedback from Advance-HTA partners.

\section{Analytical framework outlining the value assessment and appraisal characteristics of HTA systems}

Existing frameworks for analysing and classifying coverage decision-making systems for health technologies were reviewed and adjusted according to the needs of the current examination, which focuses on the assessment and appraisal stages of the coverage review procedure from the HTA agency's or institution's point of view, without having any special interest on the decision outcomes per se [21-23].

The main value assessment and appraisal characteristics necessary to outline the practices and processes in the different countries of interest as reflected through their national HTA agencies were classified using an analytical framework consisting of four key components, each having a number of different sub-components: (1) 'Responsibilities and structure of HTA agencies'; (2) 'Evidence and evaluation criteria considered in HTAs'; (3) 'Methods and techniques applied in HTAs'; and (4) 'Outcomes and implementation of HTAs'. These were considered to be the main components needed in order to sufficiently capture the features of the different HTA systems.

In the context of this study, the second component was more extensively examined because a key subject of our investigation was to identify and analyse any additional concerns and evaluation criteria beyond those informing 


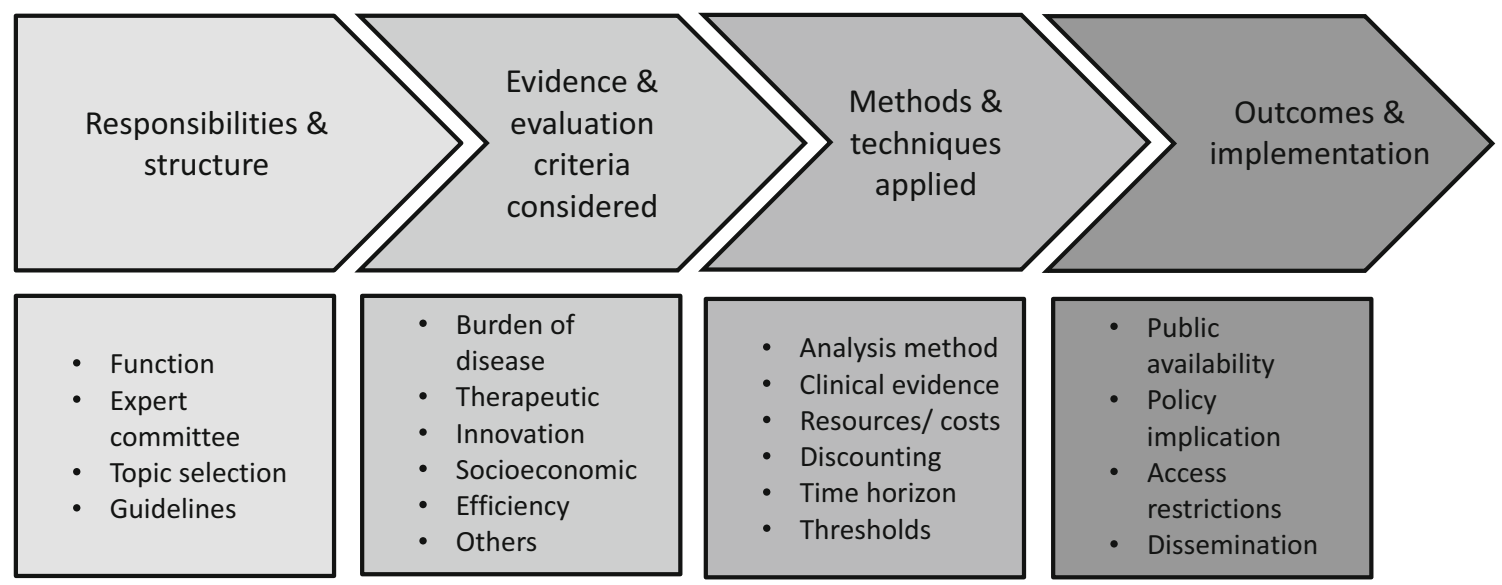

Fig. 1 Main components and sub-components of the analytical framework applied

economic evaluations or clinical benefit assessment. The sub-components of the main components are described below and are shown in Fig. 1.

\section{Responsibilities and structure of HTA agencies}

The first component considers the operational characteristics of national HTA agencies. It includes details about the function and responsibilities of HTA agencies, the relevant committees within agencies tasked with assessment and appraisal, details on the topic selection process, and whether methodological guidelines exist for the conduct of pharmacoeconomic analysis.

\section{Evidence and evaluation criteria considered in HTAs}

This component relates to the types of evidence evaluated and the particular evaluation criteria considered. Generally, the assessed evidence can be classified into features relating to the disease (indication) under consideration, or into characteristics relating to the technology being assessed. The former is reflected through the 'burden of disease' $(\mathrm{BoD})$, i.e. the impact that the disease has, which depends mainly on the severity of the disease and the unmet medical need. The latter can be classified into clinical benefit (mainly therapeutic impact and safety considerations), innovation (e.g. clinical novelty and nature of treatment), and socioeconomic impact (e.g. public health impact, productivity loss impact). Other important characteristics relate to efficiency (e.g. cost-effectiveness, cost), ethical/equity considerations, accepted data sources, and relative importance (i.e. weighting) of the evidence.

\section{Methods and techniques applied in HTAs}

This component is associated with the evaluation methods and techniques used. In terms of the analytical methods applied (i.e. comparative efficacy/effectiveness, type of economic evaluation), methodologies differ based on their outcome measure and their elicitation technique, the choice of comparator(s) and the perspective adopted. In relation to the clinical evidence used to populate the analysis, crucial details involve accepted or preferred data sources (i.e. study designs), data collection approaches (e.g. requirement for systematic literature reviews) and synthesis (e.g. suggestion for meta-analysis) of the data. In terms of resources used, important considerations include the types of costs and data sources. For both clinical outcomes and costs, discount rate(s) applied and time horizons assumed are included, together with the existence of any explicit or implicit willingness-to-pay (WTP) thresholds on cost-effectiveness based on which recommendations are made.

\section{Outcomes and implementation of HTAs}

The final component relates to the outcomes of the evaluation procedures and their implementation. Key characteristics include the public availability of the evaluation report; the policy implications of whether and how outcomes are applied in practice (e.g. pricing vs. reimbursement); the usage of any access restrictions; how decisions are disseminated and implemented; whether appeal procedures are available; and the frequency of any recommendation revisions.

\section{Systematic literature review}

The systematic literature review methodology was based on the Centre for Reviews and Dissemination (CRD) guidance for undertaking systematic reviews in health care [24].

Inclusion criteria (country selection and study period)

The study countries (and the respective HTA agencies) were France (Haute Autorité de Santé, HAS), Germany 
(Institut für Qualität und Wirtschaftlichkeit im Gesundheitswesen, IQWiG), Sweden (Tandvårds- och läkemedelsförmånsverket, TLV), England (National Institute for Health and Care Excellence, NICE), Italy ${ }^{1}$ (Agenzia Italiana del Farmaco, AIFA), the Netherlands [Zorginstituut Nederland, ZIN (formerly College voor zorgverzekeringen, CVZ)], Poland (The Agency for Health Technology Assessment and Tariff System, AOTMiT) and Spain [Red de Agencias de Evaluación de Tecnologías Sanitarias y Prestaciones del Sistema Nacional de Salud (RedETS) and the Interministerial Committee for Pricing (ICP)]. ${ }^{2}$ The study countries were selected because of their variation in health system financing (tax-based vs. social insurance-based), the organisation of the health care system (central vs. regional organisation), the type of HTA in place (predominantly economic evaluation vs. predominantly clinical benefit assessment), and the perspective used in HTA (health system vs. societal), so that the sample is representative of different health systems and HTA approaches across Europe.

The study period for inclusion of relevant published studies was from January 2000 to January 2014, with article searches taking place in February 2013 in the first instance and an update taking place at the end of January 2014. The year of 2000 was selected as the start date because the HTA activity of most countries started then or was significantly expanded in scope since then. Feedback from the Advance-HTA consortium partners was provided in August 2014. Additional input, including the most recent updates on national HTA processes, was collected from HTA experts and national competent authorities between March and May 2016.

\section{Identification of evidence}

Two electronic databases (MEDLINE - through PubMed resource-and the Social Science Citation Index-through the Web of Science portal) were searched for peer-reviewed literature only using a search strategy for English articles published up until the time of the literature search (including

\footnotetext{
${ }^{1}$ Other HTA agencies exist on regional level (e.g. UVEF is responsible for HTAs in the Veneto region).

2 RedETS is the Spanish Network of regional HTA agencies coordinated by Institutde Salud Carlos III (ISCIII) and could be regarded as the National HTA advisory body at federal level. However, at this (federal) level it does not assess pharmaceuticals, but mostly non-drug health technologies, such as screening programmes and medical devices. Although the ICP, led by the Dirección General de Farmacia under the Ministry of Health, is the committee responsible for the assessment of drugs, producing mandatory decisions at federal level regarding the reimbursement and pricing of pharmaceuticals, the vast majority of economic evaluations for drugs are conducted at autonomous community level by regional HTA agencies.
}

all results from the oldest to the latest available) using the following keywords: 'health technology assessment + pharmaceuticals'; 'health technology assessment + methodologies'; 'value assessment + pharmaceuticals'; and 'value assessment + methodologies'. Furthermore, reference lists from the studies selected were screened (see following section), retrieving any additional studies cited that could be of relevance. Finally, grey literature was searched including published guidelines from the HTA agencies available online through each agency's website.

\section{Study selection and data extraction}

Articles were selected according to a four-stage process as outlined in Fig. 2 [24]. In the first stage, all titles and abstracts were reviewed, with abstracts not relevant to the topic excluded; where content relevance could not be determined, articles were passed through to the next stage. In the second stage, all relevant abstracts were assessed against a number of pre-determined selection criteria by two of the authors; these criteria included: (1) language (only English articles were included), (2) study country (only studies examining the eight countries of interest were included), (3) study context (only national coverage HTA perspectives were included), (4) study type (productspecific technology appraisal reports were excluded), (5) record type (conference proceedings or titles with no abstracts available were excluded). In the third stage, full articles for all abstracts meeting the eligibility criteria were retrieved; in addition, relevant studies identified from reference screening and grey literature, including published guidelines from HTA agencies, were incorporated (nonEnglish articles cited by English documents were included in this stage). Finally, in the fourth stage, full articles were reviewed and relevant data were extracted. An Excel template listing the value assessment and appraisal characteristics (categories and sub-categories) of interest was used for data extraction. Data were extracted in free text form, with no limitations on the number of free text fields, and as little categorisation of data as possible, in order to avoid loss of information. The lead author extracted the data while the other authors independently checked the extracted templates for completeness and accuracy.

\section{Expert consultation}

Upon consultation of the preliminary results with the partners of the Advance-HTA consortium, it became obvious that in a few cases (primarily for France and to a lesser degree for Sweden), the evidence from the peer review literature was outdated and did not reflect actual practices, being even contradictory in some cases. As a result, we solicited comments and feedback from the 


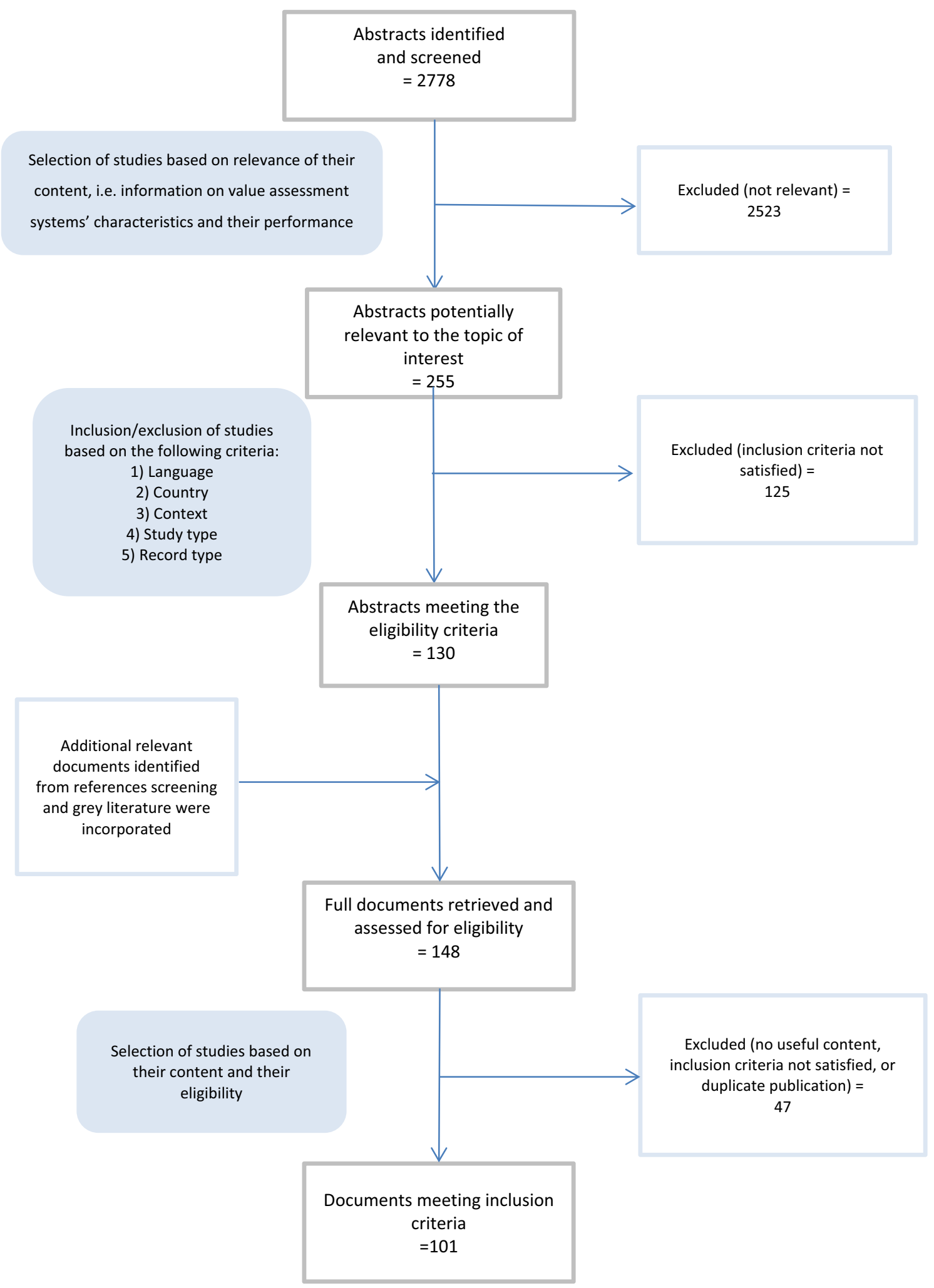

Fig. 2 Flow chart of literature review process

consortium partners in order to update and supplement the information extracted from the systematic review. In a final step, all updated results tables were shared with HTA experts in the study countries, who were asked to review and validate the outputs of the study. Experts $(n=18)$ were affiliated with academic or research institutions $(36 \%$ 
of total) and national competent authorities, such as HTA agencies or payer bodies (64\% of total), and provided further evidence and guidance, including - in some casesadditional literature sources outside the originally selected review period, if appropriate. Expert input from these two rounds of consultation are quoted as 'personal communication' from the Advance-HTA project [25].

\section{Results}

Figure 2 shows a flow chart of the review process and the respective number of articles in each stage. In total, 2778 potentially eligible peer-reviewed article listings were identified in the electronic databases; of these 255 articles were identified as potentially useful and were read in full. A total of 130 articles met the eligibility criteria, and an additional 18 articles were identified as possibly relevant through reference screening or as grey literature. The content of 101 articles from the literature review was finally used to inform the findings (Supplementary Appendix 1). An additional five studies were identified during the expert consultation process and were taken into consideration in discussing and interpreting the results (Supplementary Appendix 2).

\section{Responsibilities and structure of national HTA agencies}

Across the study countries, HTA agencies exist mainly in the form of autonomous governmental bodies, having either an advisory or regulatory function. Usually, a technical group is responsible for early assessment of the evidence following which an expert committee appraises the request for coverage and produces recommendation(s) for the final decision body.

The topic selection process is generally not entirely transparent, with the belief that most agencies predominantly assess new medical technologies that are expensive and/or with uncertain benefits. In some cases, topic selection is not applicable as all technologies that apply for reimbursement need to be assessed.

In all study countries, with the exception of Italy and Spain, official country-specific pharmacoeconomic guidelines for the evaluation process are available, mainly concerning methodological and reporting issues [26, 27]. In England, in addition to the evaluation process, guidelines also exist for the purpose of application submission requirements, including the description of key principles of the appraisal methodology adopted by NICE [27]. For all countries, application of the guidelines is recommended. It is worth clarifying that although some of the HTA agencies tend to focus on medicines, others evaluate all types of health care interventions; in this case the term "pharmacoeconomic" might not be adequately representative of the types of guidelines in place, in which case they could be referred to as "methods for HTA" as in the case of NICE. A summary of the responsibilities and structure of the national HTA agencies in the study countries is presented in Table 1.

\section{Evidence and evaluation criteria considered in HTAs}

Generally all countries assess the same groups of evidence, however the individual parameters considered and the way they are evaluated differ from country to country. All countries acknowledge the consideration of a wide variety of data sources including scientific studies (e.g. clinical trials, observational studies), national statistics, clinical practice guidelines, registry data, surveys, expert opinion and other evidence from pharmaceutical manufacturers [28]. A summary of the evidence and the evaluation criteria under consideration across the study countries is presented in Table 2.

\section{Evaluation principles and their relevance to priority setting}

In France, the assessment of the product's medical benefit or medical service rendered (Service Médical Rendu, SMR), and improvement of medical benefit (Amélioration du Service Médical Rendu, ASMR), determine a new drug's reimbursement and pricing respectively. As of October 2013, economic criteria have been introduced with the Commission for Economic Evaluation and Public Health (CEESP) evaluating the cost-effectiveness (without a costeffectiveness threshold in place) of products assessed to have an ASMR I, II or III that are likely to impact social health insurance expenditures significantly (total budget impact greater than EUR 20 million); results are used by the Economic Committee for Health Products (CEPS) in its price negotiations with manufacturers [29]. Nevertheless, and under this current framework, these economic evaluations do not have the same impact on price negotiation as does the ASMR, which is linked directly to pricing. Instead, the role of economic evaluations is consultative in this process.

In Germany, the new Act to Reorganize the Pharmaceuticals Market in the Statutory Health Insurance (SHI) System [Gesetz zur Neuordnung des Arzneimittelmarktes in der gesetzlichen Krankenversicherung (AMNOG)] came into effect on 1 January 2011. Since then, all newly introduced drugs are subject to early benefit assessment. 


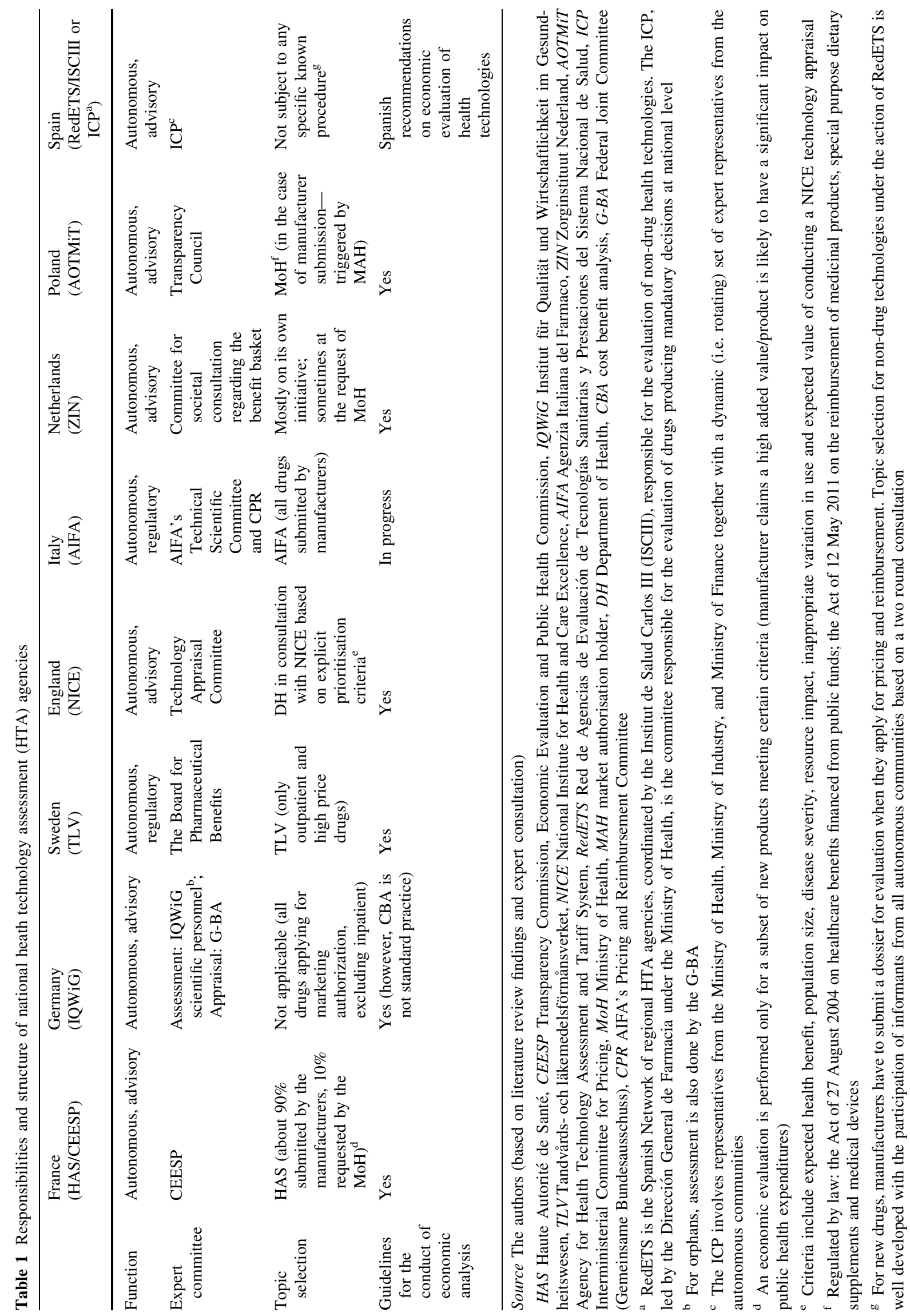




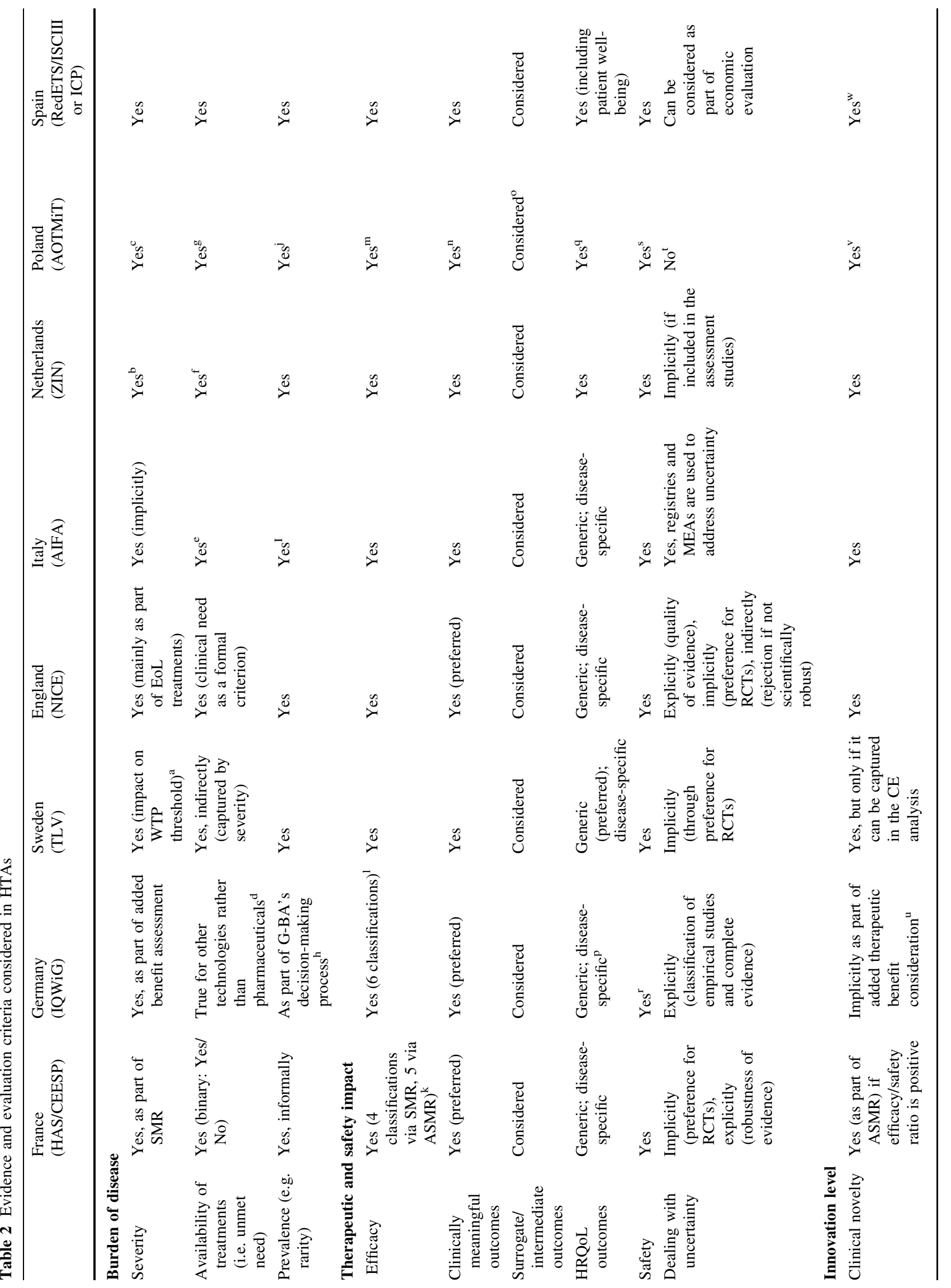




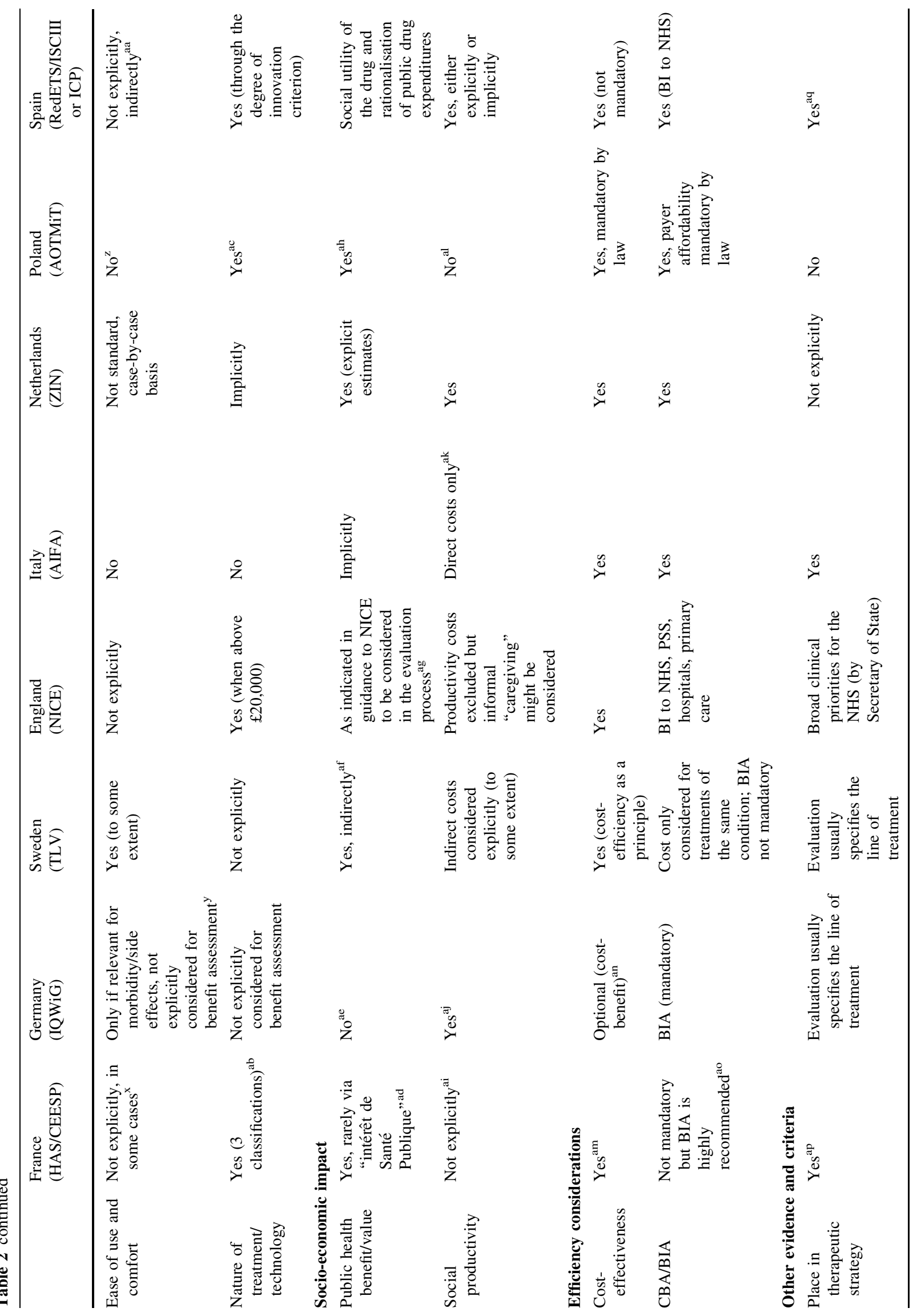




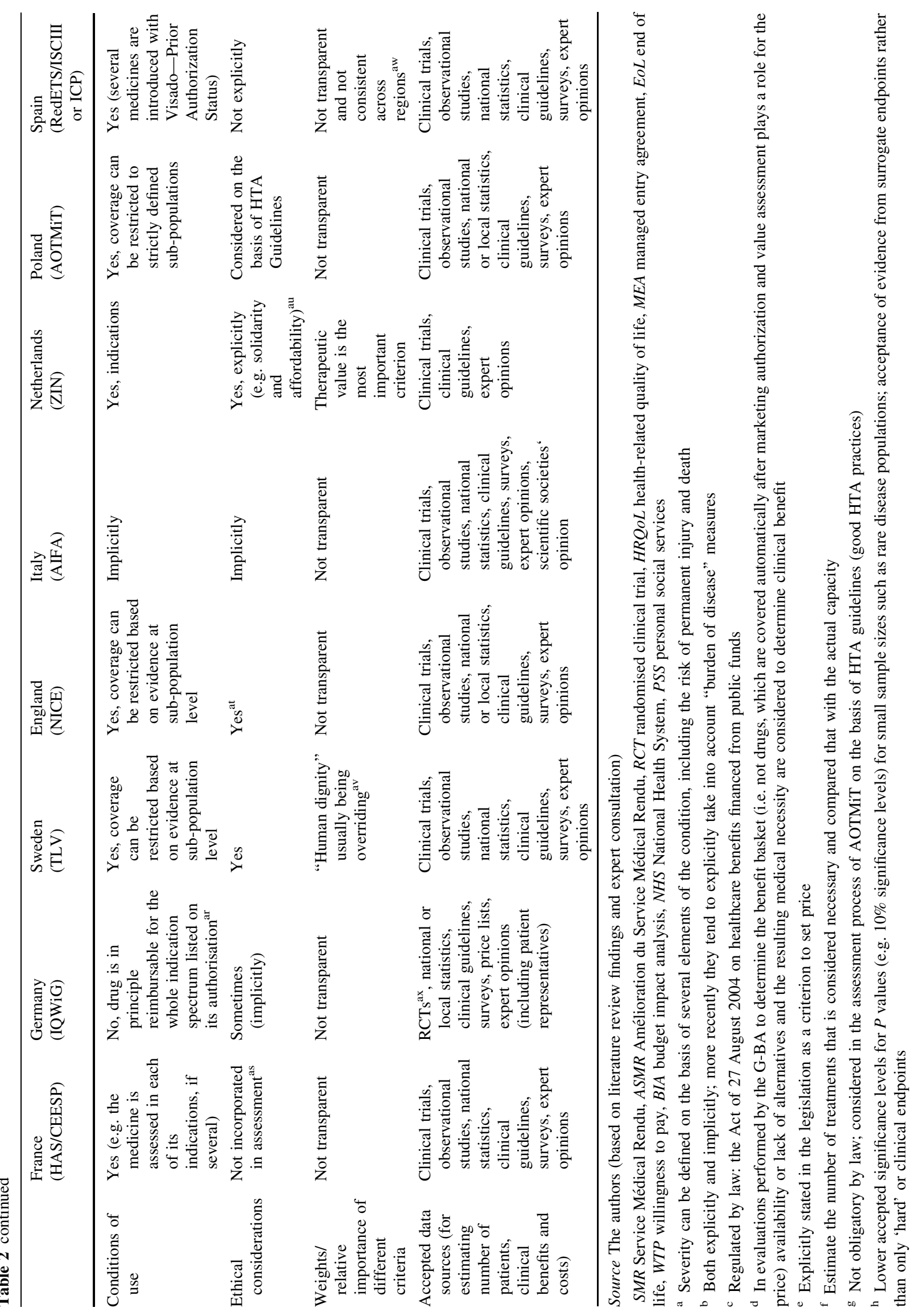




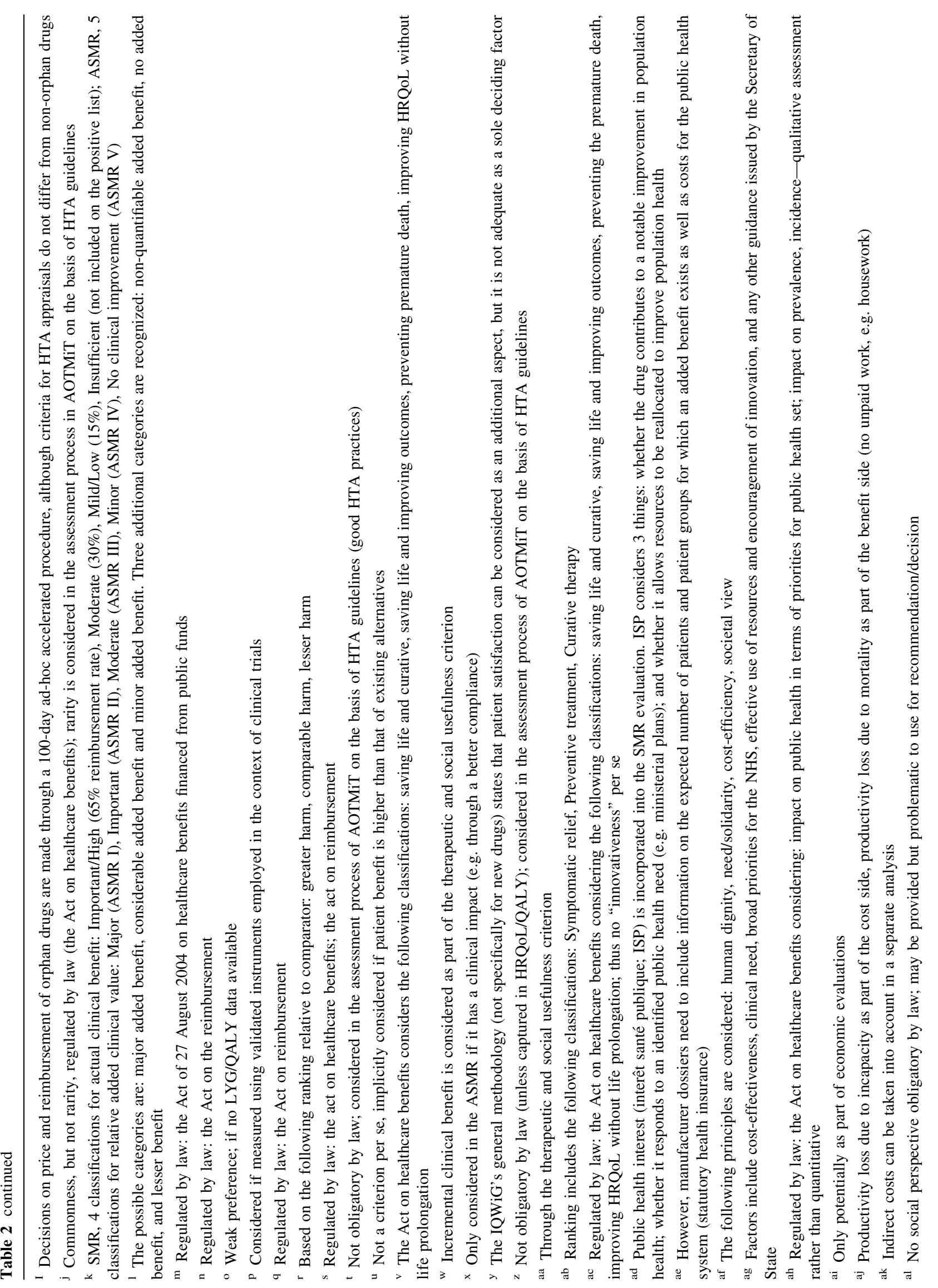




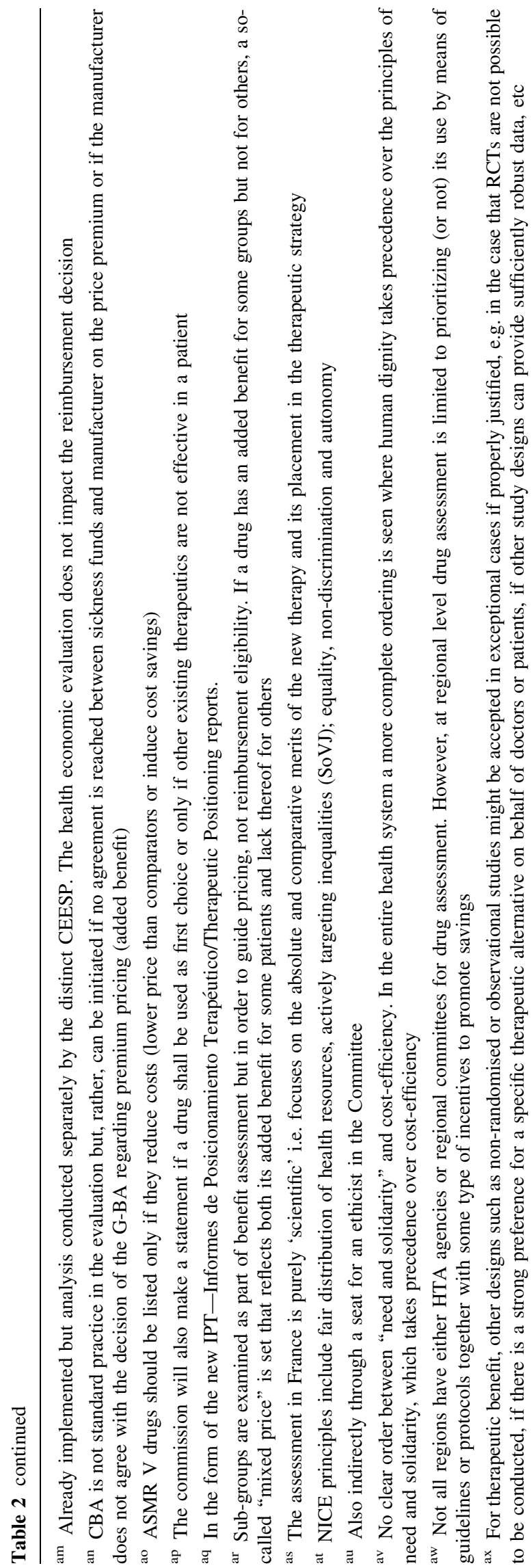

Pharmaceutical manufacturers have to submit a benefit dossier for evaluation by the IQWiG. A final decision is made by the Federal Joint Committee (Gemeinsamer Bundesausschuss, G-BA). Benefit for new drugs encompasses the "patient-relevant therapeutic effect, specifically regarding the amelioration of health status, the reduction of disease duration, the extension of survival, the decrease in side effects or the improvement of quality of life" [30]. Importantly, all new drugs are reimbursed upon marketing authorisation, with benefit assessment mainly determining price rather than reimbursement status.

In Sweden, a prioritisation framework with three explicit factors for the allocation of resources is used: (1) human dignity; (2) need and solidarity; and (3) cost-efficiency [31-34]. However, in the specific legislation for the pharmaceutical reimbursement system, human value is generally seen as the overriding criterion with no clear order between the other two [25]. Marginal benefit or utility, according to which a diminishing cost-effectiveness across indications and patient groups is explicitly recognized, could be regarded as a fourth principle, mainly meaning that there are no alternative treatments that are significantly more suitable $[31,35,36]$.

In England, the Secretary of State for Health has indicated to NICE a number of factors that should be considered in the evaluation process: (1) the broad balance between benefits and costs (i.e. cost-effectiveness); (2) the degree of clinical need of patients; (3) the broad clinical priorities for the NHS; (4) the effective use of resources and the encouragement of innovation; and (5) any guidance issued by the Secretary of State [37-39]. Decisions are supposed to reflect societal values, underlined by a fundamental social value judgment [40].

The Netherlands focuses on four priority principles when assessing medical technologies: (1) the "necessity" of a drug (severity/burden of disease) [41, 42]; (2) the "effectiveness" of a drug, according to the principles of evidence-based medicine (EBM) [42, 43]; (3) the "costeffectiveness" of a drug [44]; and (4) "feasibility", i.e. how feasible and sustainable it is to include the intervention or care provision in the benefits package $[45,46]$.

In Italy, reimbursement of pharmaceuticals at the central level is evaluated by AIFA's Pricing and Reimbursement Committee (CPR), which sets prices and reimbursement conditions for drugs with a marketing authorisation based on evidence of the following factors: the product's therapeutic value (cost/efficacy analysis) and safety (pharmacovigilance), the degree of therapeutic innovation, internal market forecasts (number of potential patients and expected sales), the price of similar products within the same or similar therapeutic category and product prices in other European Union Member States [25]. In autonomous regions, pricing and reimbursement of new drugs does not 
require-except for very innovative drugs—epidemiologic or economic evaluation studies nor assessment of cost impact from the adoption of new drugs, as in other countries [25, 47].

An HTA in Poland is considered complete if it contains (1) a clinical effectiveness analysis; (2) an economic analysis; and (3) a healthcare system impact analysis. No studies were available from the systematic review referring to the evidence assessed or the different parameters considered by AOTMiT in Poland [48].

Finally, in Spain different regions apply a range of different assessment requirements, but in general four main evidence parameters are considered: (1) the severity of the disease; (2) the therapeutic value and efficacy of the product; (3) the price of the product; and (4) the budget impact for the Spanish National Health System. The assessment is usually a classification or a cost-consequences analysis that does not take into account the long-term effects of a therapy or the possible need of specialized care utilization. Patient well-being and quality of life are also considered [49].

\section{Evaluation criteria taken into account in HTAs}

Burden of disease In France, both the severity and the existence of alternative treatments act as formal criteria, thus essentially defining the concept of 'need' [41]. Severity is considered as part of the SMR, taking into account symptoms, possible consequences, including physical or cognitive handicap, and disease progression in terms of mortality and morbidity [25]. The existence of alternatives is scored against a binary scale (yes vs. no) $[50,51]$.

In Germany, severity is considered as part of added (clinical) benefit assessment. The clinical assessment is based on "patient-relevant" outcomes, mainly relating to how the patient survives, functions or feels, essentially accounting for the dimensions of mortality, morbidity and HRQoL [52].

In Sweden, severity of the condition and the availability of treatments reflected through marginal benefit/utility as a sub-principle appear to be two of the primary criteria for priority-setting, with more severe indications being explicitly prioritized via greater willingness to pay (WTP) [31, 35, 36, 41].

In England, the degree of unmet clinical need is a formal criterion taken into account, being reflected by the availability of alternative treatments [41, 53]. NICE acknowledges that rarity plays a key role in the assessment of orphans and NICE's Citizens' Council has stated that society would be willing to pay more for rare and serious diseases [54]. The severity of the disease is taken into account mainly through the special status of life-extending medicines for patients with short-life expectancy as reflected through the issuing of supplementary advice of life-extending end-of-life (EOL) treatments by NICE $[53,55]$.

Severity of disease, availability of treatments, and prevalence of the disease are generally considered across the remaining countries, either explicitly or implicitly, although not always as mandatory requirements by law but just as good HTA practices (e.g. as in Poland for the case of treatments availability) [25].

Therapeutic impact and safety Clinical evidence relating to therapeutic efficacy and safety acts as the most important formal criterion of the evaluation process in France [56]. The product's SMR relates to the actual clinical benefit, responding to the question of whether the drug is of sufficient interest to be covered by social health insurance. It takes into consideration the following criteria: (1) the seriousness of the condition; (2) the treatment's efficacy; (3) side effects; (4) the product's position within the therapeutic strategy given other available therapies; and (5) any public health impact $[25,27]$.

Similarly to France, in Germany all clinically relevant outcomes are considered and final clinically meaningful outcomes (e.g. increase in overall survival, reduction of disease duration, improvement in HRQoL) are preferred over surrogate and composite endpoints $[27,28,52,57$, 58]. HRQoL endpoints are considered if measured using validated instruments suited for application in clinical trials $[25,30]$. With regards to uncertainty, IQWiG ranks the results of a study according to "high certainty" (randomized study with low bias risk), "moderate" (randomized study with high bias risk), and "low certainty" (non-randomized comparative study). The complete evidence base is then assessed and a conclusion is reached on the probability of the (added) benefit and harm, graded according to major added benefit, considerable added benefit, and minor added benefit. Three additional categories are recognized: non-quantifiable added benefit, no added benefit, and lesser benefit $[25,52]$.

All types of clinically relevant outcomes are accepted in Sweden, including final outcomes, surrogate endpoints, and composite endpoints, with generic QoL endpoints being preferred over disease-specific endpoints [25, 57]. Generally, all effects of a person's health and QoL are supposed to be considered as part of the assessment stage, including treatment efficacy and side effects [35, 36, 56].

In England, data on all clinically relevant outcomes are accepted with final clinical outcomes (e.g. life years gained) and patient HRQoL being preferred over intermediate outcomes (e.g. events avoided) or surrogate endpoints and physiological measures (e.g. blood glucose levels) [57, 59-61]; particular outcomes of interest include 
mortality and morbidity. Safety is addressed mainly through the observation of adverse events [53]. Uncertainty is addressed explicitly through quality of evidence, implicitly through preference for RCTs, and indirectly by rejecting a submission if evidence is not scientifically robust.

Italy, the Netherlands, Poland and Spain include surrogate and composite endpoints in the analysis, in addition to disease-specific quality of life endpoints. Therapeutic value is the most critical criterion for reimbursement in the Netherlands, as part of which patient preference data and user friendliness may also be considered [43].

All countries take into consideration safety data to reflect clinical harm, mainly in the form of the incidence and severity of adverse events.

Innovation level In the French setting, clinical novelty is considered by definition through the product's ASMR relating to its relative added clinical value, which informs pricing negotiations [25]. Additional innovation characteristics relating to the nature of the treatment (e.g. differentiating between symptomatic, preventive and curative) are also considered, but as a second line of criteria $[25,56,61,62]$.

In Germany, clinical novelty is considered implicitly as part of the consideration of added therapeutic benefit for premium pricing. Ease of use and comfort (if relevant for morbidity or side effects) can be reflected indirectly through treatment satisfaction for patients, which can be considered as an additional aspect but not as an explicit factor, similarly to the nature of the treatment/technology [63].

In Sweden, innovation characteristics relating to the added therapeutic benefit (only if it can be captured in the $\mathrm{CE}$ analysis), as well as ease of use and comfort are included in the assessment process [25, 41, 56, 61].

As reflected through NICE's operational principles, the encouragement of innovation is an important consideration in England. By definition, the incremental therapeutic benefit as well as the innovative nature of the technology are formally taken into account as part of the product's incremental cost effectiveness ratio (ICER) [53].

Among the remaining countries, clinical novelty is essentially considered in all countries; ease of use and comfort might only be considered implicitly and informally if at all, whereas there are mixed approaches in terms of a treatment's technology nature.

Socioeconomic impact In terms of socioeconomic parameters, in France 'expected' public health benefit acts as another explicit dimension via an indicator known as public health interest ("Intérêt de Santé Publique", ISP), which is assessed and scored separately by a distinct committee as part of the SMR evaluation but not used often $[25,41,62,64]$.

In Germany, public health benefit is not explicitly considered but only partially reflected through the requirement from manufacturers to submit information on the expected number of patients and patient groups for which an added benefit exists, as well as costs for the public health system (statutory health insurance) [25, 63]. All direct costs have to be considered, including both medical and non-medical (when applicable), whereas indirect costs are not a primary consideration but can be evaluated separately if they are substantial, with productivity losses due to incapacity being included only on the cost side [65]. In turn, productivity losses due to mortality are considered in the outcome only on the benefit side (to avoid double counting). Budget impact analysis (BIA) is mandatory and should include any one-off investments or start-up costs required in order to implement a new technology, with methodology and sources clearly outlined [27, 65].

Among the other study countries, any public health impact of the drug is usually considered, but not necessarily in an explicit manner, whereas social productivity might be reflected through the incorporation of indirect costs, either explicitly or implicitly [25]. In England for example, although productivity costs should be excluded, cost of time spent on informal caregiving can be presented separately if this care might otherwise have been provided by the NHS or personal social services (PSS) [66].

Efficiency In France, up until now cost-effectiveness was not acknowledged as an explicit or mandatory criterion, but BIA, while not mandatory, is highly recommended [25]. Although the expert committee had been reluctant to use cost-effectiveness criteria in the evaluation process [56, 67], following a bylaw passed in 2012 (which took effect in 2013) the role of economic evidence was strengthened [51]. The CEESP gives an opinion on the efficiency of the drug based on the ASMR of alternative treatments.

In Germany, economic analysis [cost-benefit-analysis (CBA)] is not standard practice in the evaluation, but, rather, is optional and can be initiated if no agreement is reached between sickness funds and the manufacturer on the price premium, or if the manufacturer does not agree with the decision of the G-BA regarding premium pricing (added benefit); instead, BIA is mandatory (Advance-HTA, 2016). 'Cost-effectiveness' acts as one of the most important formal evaluation criteria in Sweden. Parameters having a socioeconomic impact, such as avoiding doctor visits or surgery, productivity impact, and, in general, savings on direct and indirect costs are also considered [35]. 
As already reflected through NICE's working principles, the relative balance between costs and benefits (i.e. valuefor-money), and the effective use of resources should be taken into account in England (e.g. through the explicit cost-effectiveness criterion) [37]. Some studies also suggest that the impact of cost to the NHS in combination with budget constraints (budget impact considerations) are taken into account alongside the other clinical and cost-effectiveness evidence [39, 67-70].

In the assessment process by ZIN, the cost-effectiveness criterion follows that of the therapeutic value and the cost consequences analysis. Cost-effectiveness is only considered for drugs with added therapeutic value, which are either part of a cluster and are reimbursed at most at the cluster's reference price, or are not reimbursed in the absence of possible clustering $[43,71]$. The Netherlands usually performs its own BIA, although voluntary submission from the manufacturer is also an option [43, 67].

All other study countries evaluate the efficiency of new drugs through cost-effectiveness evaluation and BIA, but this is not always mandatory or an explicit criterion in value assessment and pricing/reimbursement negotiations.

Other types of evidence Additional explicit parameters considered in France include the technology's place in the therapeutic strategy, mainly in relation to other available treatments (i.e. first-line treatment vs. second-line treatment etc.), and the technology's conditions of use $[25,50,51]$.

Germany is the only country that does not apply any conditions of use in regards to specific sub-populations, in principle reimbursing drugs across the whole indication spectrum as listed on the marketing authorisation [25]. Nevertheless, recent IQWiG appraisals increasingly focus on providing value assessments at sub-population level.

As reflected through the ethical prioritisation framework used by the Swedish TLV, the ethical considerations of human dignity, need and solidarity act as principles for the evaluations.

Besides the notion of clinical need as reflected through NICE's principles, other equity considerations include the 'need to distribute health resources in the fairest way within society as a whole' and the aim of 'actively targeting inequalities', both of which are explicitly mentioned by NICE as principles of social value judgements [37]. Equality, non-discrimination, and autonomy are other explicit ethical considerations [41].

The Netherlands also takes into consideration explicitly ethical criteria based on egalitarian principles, such as solidarity and affordability of the technology by individual patients $[25,33,41]$.
In terms of the remaining countries, conditions for use may be placed in Italy, Poland and Spain, the therapy's place in therapeutic strategy considerations exist for Italy and Spain, whereas ethical considerations are evident in Italy and Poland (implicitly or indirectly). However, the use of any additional explicit parameters may not be transparent in these settings.

\section{Synthesizing the evidence and taking into account all factors: weights}

It is not clear how all the factors discussed so far interact with one another, what their relative importance is and what the trade-offs are that HTA agencies are prepared to make between them when arriving at recommendations [70, 72]. For example, in France the weights of the assessment parameters considered and the appraisal process overall do not seem to be clear or transparent [56], although the evidence that informs this judgment is dated and may be contestable. In Spain, the assessment takes into account mainly safety, efficacy, effectiveness, and accessibility and it does not consider explicitly efficiency and opportunity cost; still the way this is undertaken and the weights of different criteria remain unknown [73]. All countries consider a number of different data sources for the assessment process, with randomised controlled trials (RCTs) usually being the most preferred source for clinical data.

\section{HTA methods and techniques applied}

Assuming the existence of an additional benefit (or lesser harm) compared to existing treatment options, all countries with the exception of France and Germany are adopting some type of economic evaluation, mainly cost utility analysis (CUA) or cost-effectiveness analysis (CEA), as the analytical tool to arrive at value-for-money recommendations aiming at improving effiency in resource allocation; both France and Germany used to apply a comparative assessment of clinical benefit as the sole methodology, with economic evaluation progressively becoming more important in France as of 2013 but in the context of the existing method of assessment. A summary of analytical methods and techniques applied as part of HTA and their details is presented in Table 3.

\section{Analytical methods}

In Sweden and England the preferred type of economic evaluation is CUA with cost per QALY gained being the favoured health outcome measure, but CEA being also accepted if there is supporting evidence to do so (as in the case that the use of QALY for a particular case seems 


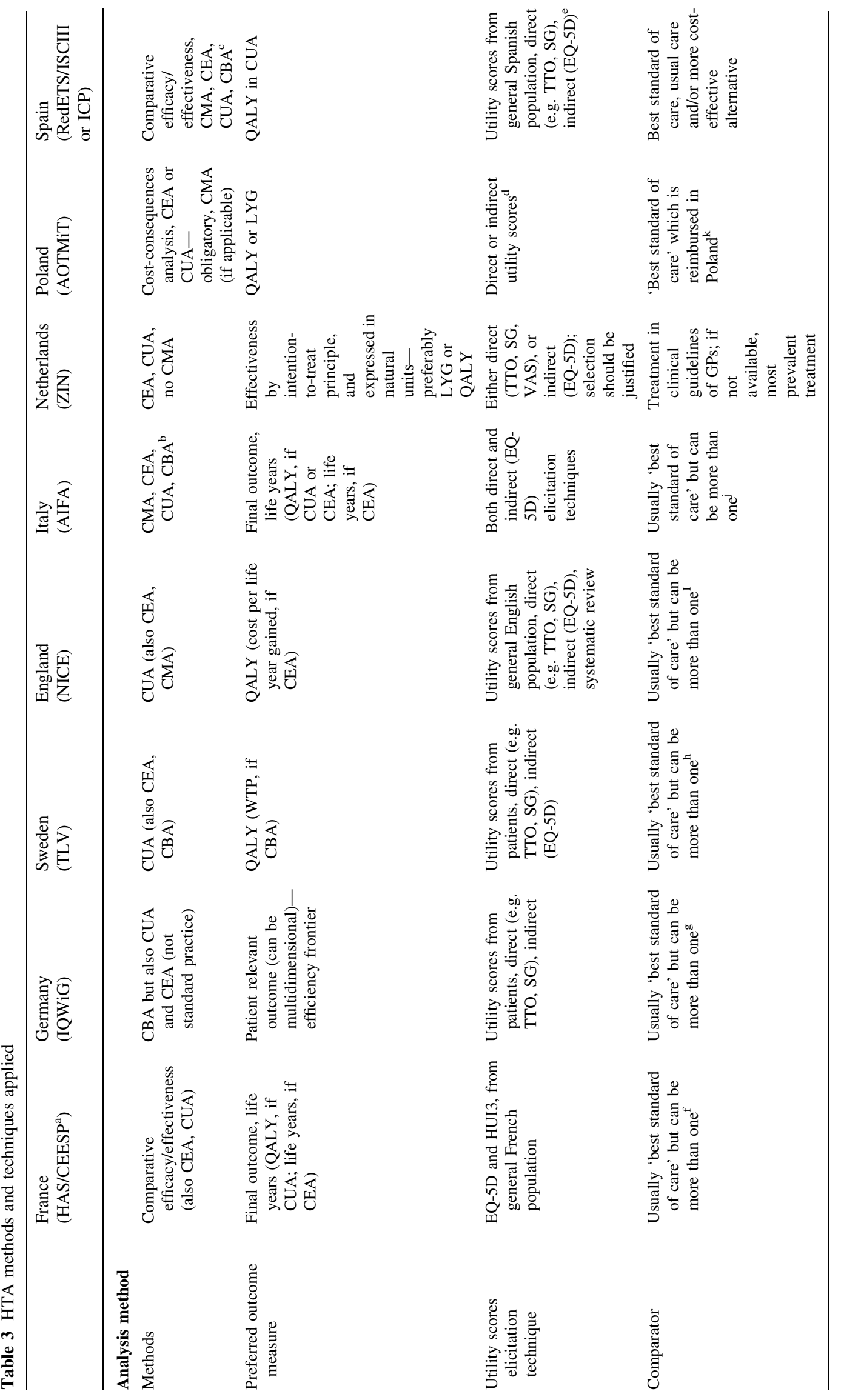




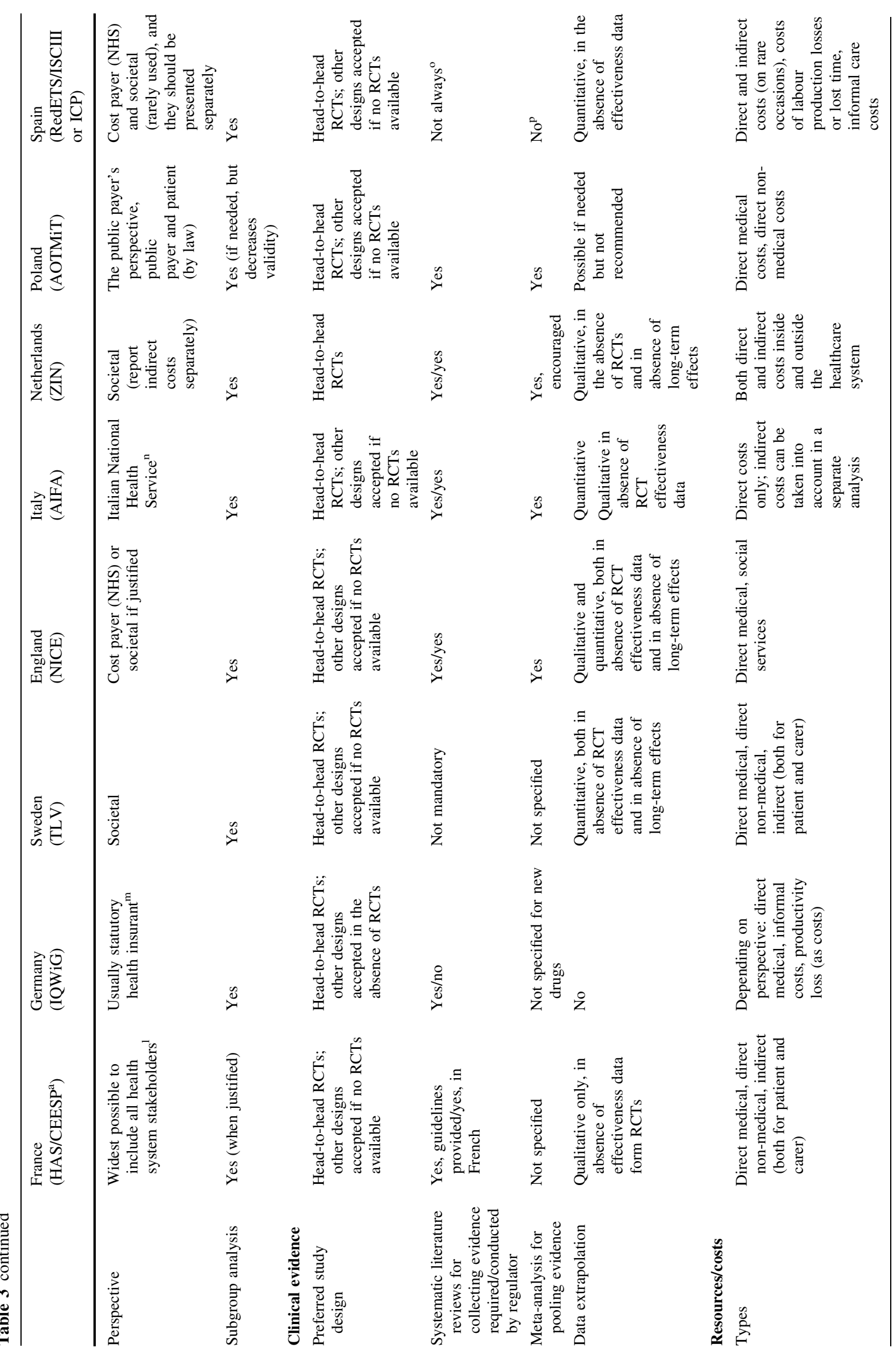




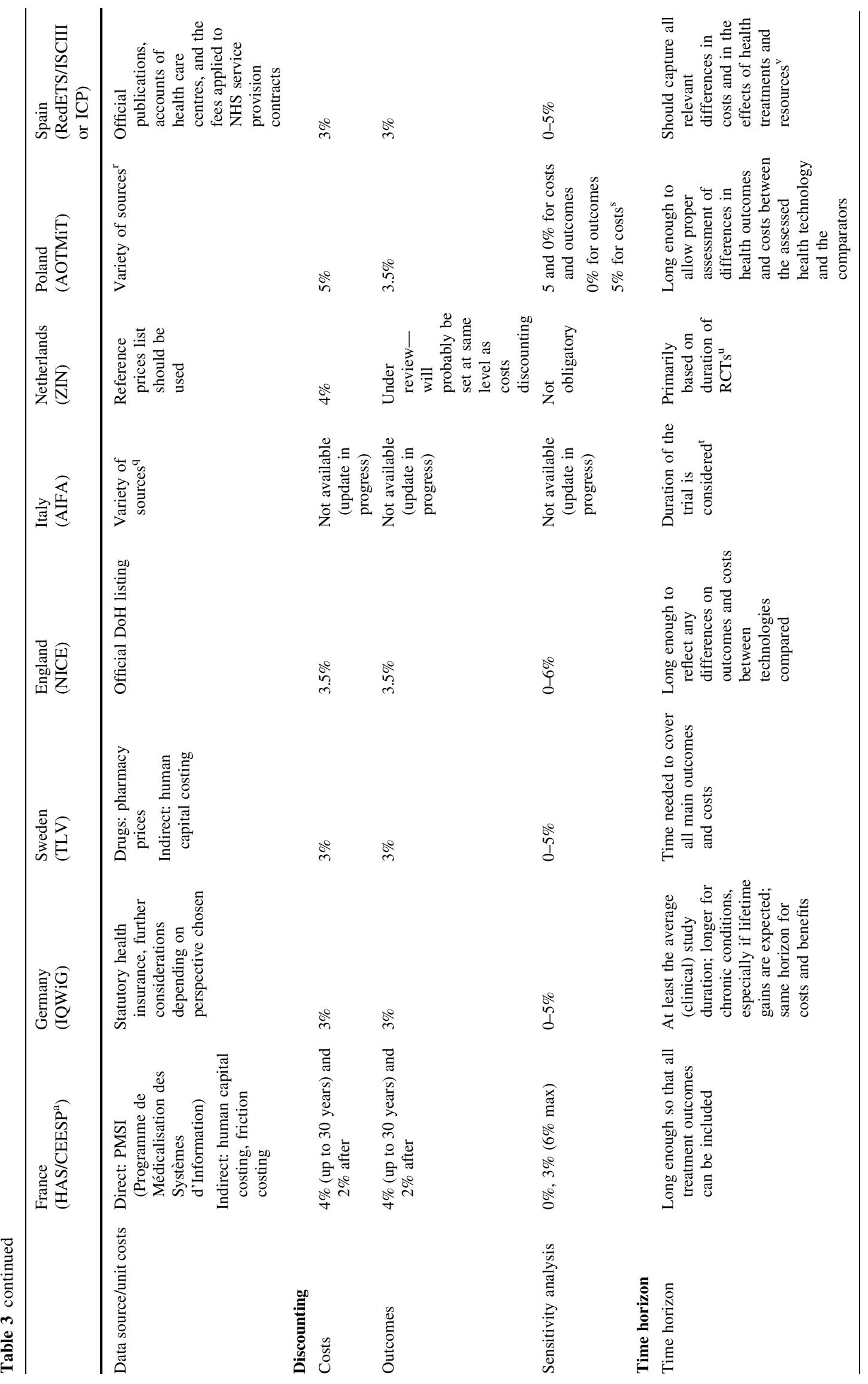




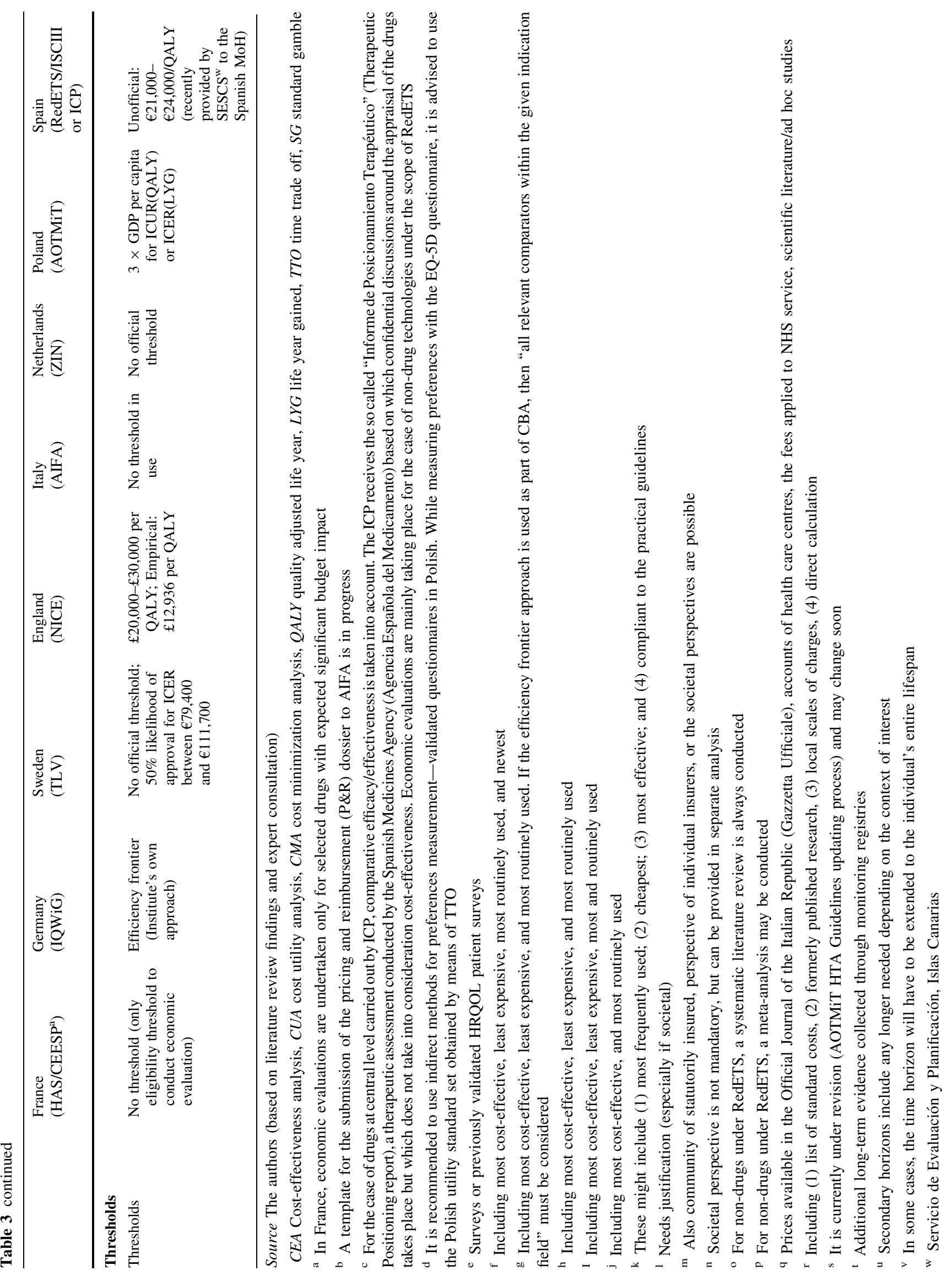


inappropriate) [27, 28, 37, 38, 60, 74-77]. In Sweden, CBA with WTP as an outcome measure can also be applied.

In France, up until now comparative assessment of clinical benefit incorporating final endpoints as an outcome measure acted as the preferred evaluation procedure. However, economic analysis of selected drugs with expected significant budget impact is continuously being considered more formally, especially if its choice is justified and any methodological challenges (especially associated with the estimation of QALYs) are successfully addressed [27, 28, 41, 50, 51, 58]. The choice between CEA and CUA depends on the nature of the expected health effects (if there is expected significant impact on HRQoL then CUA is used, otherwise CEA).

In Germany, economic evaluations are performed within therapeutic areas and not across indications, thus, an efficiency frontier approach of CBA using patient relevant outcomes is the preferred combination of analysis method and outcome measure [22, 27, 28, 58, 65]. Since the introduction of the AMNOG, economic evaluations are supposed to be conducted for cases when price negotiations fail after the early benefit assessment and the verdict is challenged by the technology supplier or the statutory health insurer [65]. However, no such analysis has been submitted so far and seems unlikely to ever happen because the CBA would have to be re-evaluated by IQWiG, which would hardly bring any better results [25].

In the Netherlands and Italy, the preferred type of economic evaluation is CUA if the improvement in quality of life forms an important effect of the drug being assessed, or if this is not the case, a CEA [78, 79]. In Spain, any of the four methods of analysis may be used (CMA, CEA, CUA or CBA).

\section{Types of clinical evidence considered}

In relation to clinical evidence, all countries acknowledge that randomised controlled head-to-head clinical trials are the most reliable and preferred source of treatment effects (i.e. outcomes), with data from less-rigorous study designs being accepted in most study countries (England, France, Germany, Sweden, Poland, Spain, Italy), e.g. when direct RCTs for the comparators of interest are not available [28, 53, 61].

Most agencies require systematic literature reviews to be submitted by manufacturers as a source of data collection, and carry out their own reviews. A meta-analysis of keyclinical outcomes is recommended for pooling the results together given the homogeneity of the evidence in England, Italy, Netherlands and Poland [28, 53].

If evidence on effectiveness is not available through clinical trials, France and the Netherlands allow for a qualitative extrapolation based on efficacy data, with Spain conducting quantitative extrapolation, and Sweden, England, Italy and Poland applying both qualitative and quantitative modelling. In Sweden, England and Netherlands, short-term clinical data are extrapolated also if data on long-term effects are absent.

\section{Resources/cost evidence}

In terms of resources used, in addition to direct medical costs, France and Sweden consider all relevant costs, including direct non-medical and indirect costs, both for patients and carers [27, 28]; however, only direct costs are considered in the reference case analysis and incorporated in the ICER in the case of France [50]. Germany also takes into account informal costs and productivity gains separately as a type of benefit, whereas England additionally considers cost of social services.

Poland incorporates direct medical costs and direct non-medical costs. In the Netherlands, the Health Care Insurance Board's "Manual for cost research" applies for the identification, measurement and valuation of costs; pharmacoeconomic evaluations need to include both direct and indirect costs inside and outside the healthcare system [78]. In Italy, it is recommended to include direct costs; indirect costs can be taken into account in a separate analysis [25]. Spain incorporates both direct and indirect costs (the latter on rare occasions), as well as costs of labour production losses or lost time and informal care costs, in the analysis [25, 58]. Finally, all countries recommend the application of country-specific unit costs [28].

\section{Discounting and time horizon}

In all study countries, both costs and benefits are discounted [27, 58, 61, 74], and uncertainty arising due to variability in model assumptions is investigated, usually in the form of a sensitivity analysis. In Italy, information on discounting is not available at the moment due to an update in progress by AIFA [25]. In terms of a suitable time horizon, none of the countries use an explicit time frame but, instead, they adopt a period that is long enough to reflect all the associated outcomes and costs of the treatments being evaluated, including the natural course of the disease $[27,80]$.

\section{Acceptable 'value for money' thresholds}

No explicit, transparent, or clearly defined cost-effectiveness thresholds exist in any of the countries except for England, Poland, and an academic proposal for Spain.

In line with the World Health Organization (WHO) suggestions of two to three times the gross domestic 
product (GDP) per capita, a three times GDP per capita threshold has been implemented in Poland. Generally, a drug is deemed cost-effective by AOTMiT if cost per QALY estimates are less than three times the GDP per capita (but smaller than 70,000 PLN per QALY/LYG) [25,81].

In Spain, a $€ 21,000-€ 24,000$ per QALY threshold was recently provided by Servicio de Evaluación y Planificación Canarias (SESCS) to the Ministry of Health; however, this might not be actively adopted in practice [25].

In England, although evidence suggests the existence of a threshold ranging somewhere between $£ 20,000$ and $£ 30,000[44,59,75,82]$, it is evident that such a threshold range might not be strictly applied in practice, with some products having a cost per QALY below these ranges receiving negative coverage recommendations, and other products above these ranges ending up with positive recommendations [60, 83, 84]. Indeed, several studies point towards the existence of a threshold range based on which additional evidence on several factors is required for the recommendation of technologies with an ICER of above $£ 20,000$, and even stronger evidence of benefit in combination with explicit reasoning required for the coverage of technologies with an ICER above $£ 30,000$ [38, 39, 44, 53, 56, 85]. However, a more recent study using data on primary care trust spending and diseasespecific mortality estimated an empirical based "central" threshold of $£ 12,936$ per QALY, with a probability of 0.89 of less than $£ 20,000$ and a probability of 0.97 to be less than $£ 30,000$ [86].

In Germany, the efficiency frontier approach is used to determine an acceptable "value for money", even though this is not involved in the process of the initial rebate negotiations. In Sweden, recent evidence suggested that the likelihood of approval is estimated to be $50 \%$ for an ICER between $€ 79,400$ and $€ 111,700$, for non-severe and severe diseases respectively [87].

In the Netherlands, there is no formal threshold in place but there have been some attempts to define one. The $€ 20,000$ per life-year gained (LYG) threshold used in the 1990s to label patients with high cholesterol levels eligible for treatment with statins has been mentioned in discussions on rationing, but was never used as a formal threshold for cost-effectiveness. The same was the case with a threshold that the Council for Care and Public Health wanted to implement based on criteria such as the GDP per capita, in line WHO recommendations, which, for the Netherlands, would translate into $€ 80,000 / Q A L Y$ [71]. The Council also suggested that the cost per QALY may be higher for very severe conditions (a tentative maximum of $€ 80,000)$ than for mild conditions (where a threshold of $€ 20,000$ or less may apply) [46], but none of the above was ever implemented.

\section{HTA outcomes and implementation}

In all countries, assessment and appraisal of outcomes are used mainly as a tool to inform coverage recommendations relating to the reimbursement status of the relevant technologies; all countries use the results to inform pricing decisions directly or indirectly. A summary of the types of HTA outcomes and their implementation in the study countries is presented in Table 4.

\section{Timing and public availability}

Generally, the time needed for the evaluation of a health technology to be completed differs from country to country. However, in line with the EU Transparency Directive, all countries must have reached a decision on pricing and reimbursement within 180 days post marketing authorisation [56]. In all countries, the final decision report is publicly available, usually through the HTA agency's website $[12,56]$, and the policy implication of the evaluation outcome relates to the pricing and reimbursement status of the technology: reimbursement (list), no reimbursement (do not list), or conditional reimbursement (list with restrictions) [56, 68].

\section{Policy implications}

In France and Sweden, only drugs with additional therapeutic value can "obtain a higher reimbursement basis" [56]; in France, by assessing the evidence of the product's medical benefit or medical service rendered (SMR), the improvement in medical benefit and added therapeutic benefit (ASMR) are derived, which determine the reimbursement status and influence the price level of the product respectively, whereas in Sweden the outcome of the evaluation can also drive the price setting in addition to coverage decisions $[35,36]$.

In Germany, the outcome of the clinical/economic evaluation will be used mainly to inform the negotiation between sickness funds and manufacturer on the price premium. In England, reimbursement status has no direct effects on price, but price indirectly affects the reimbursement status of the drug as it will have an impact on the ICER. In the Netherlands, the positive outcome of an HTA results in the inclusion of the medical technology in the positive list [43]; in terms of the reimbursement decision, if the CEA for a new innovative drug is of high quality, reimbursement will in principle not be denied on the basis of cost-effectiveness, despite potentially relatively high cost-per-QALY values [71]. Finally, in Italy, if a reimbursement status is approved, the pricing is decided simultaneously. If the reimbursement decision is negative, the product will be put on the negative list and the price is determined by the manufacturer ("free pricing"). 


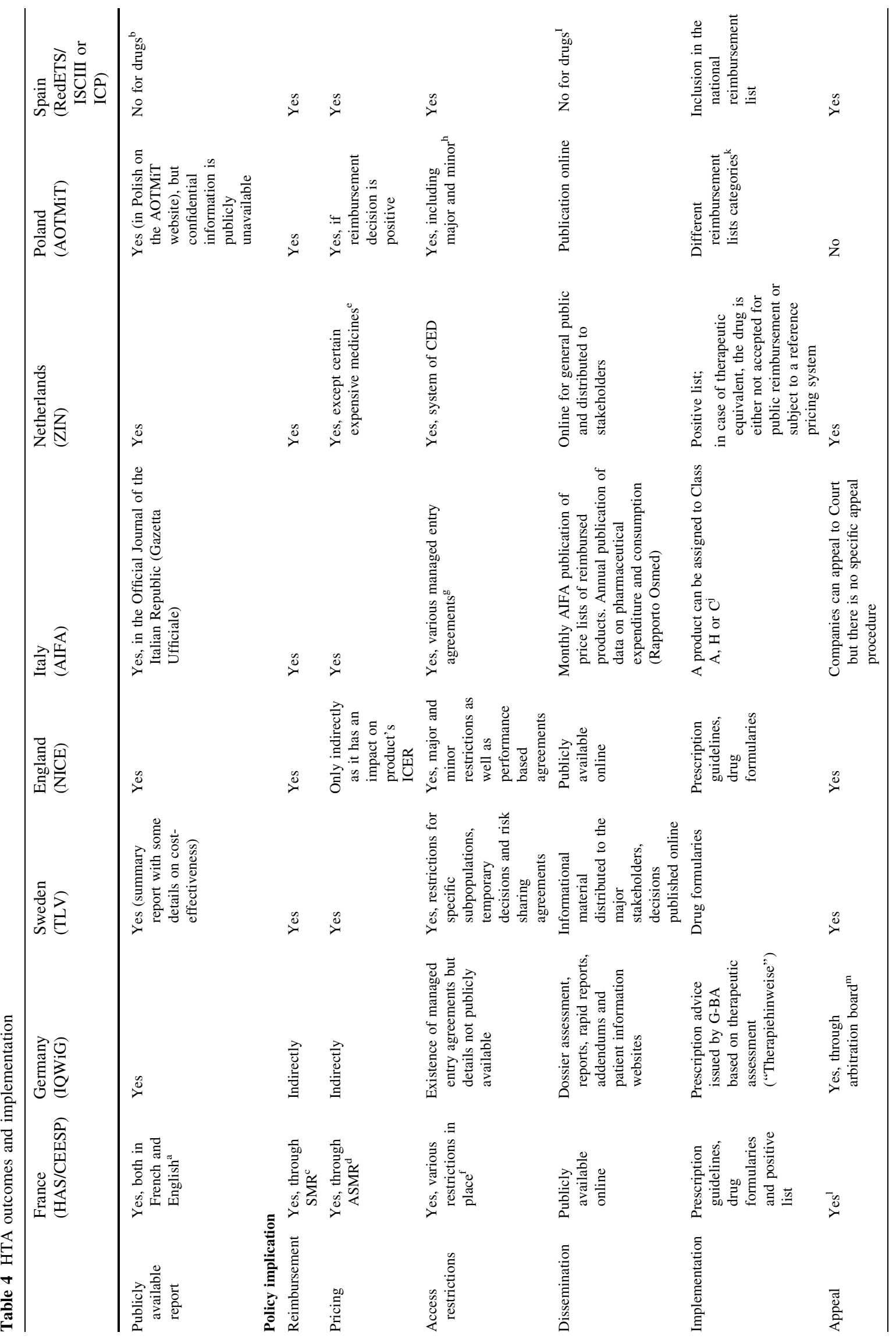




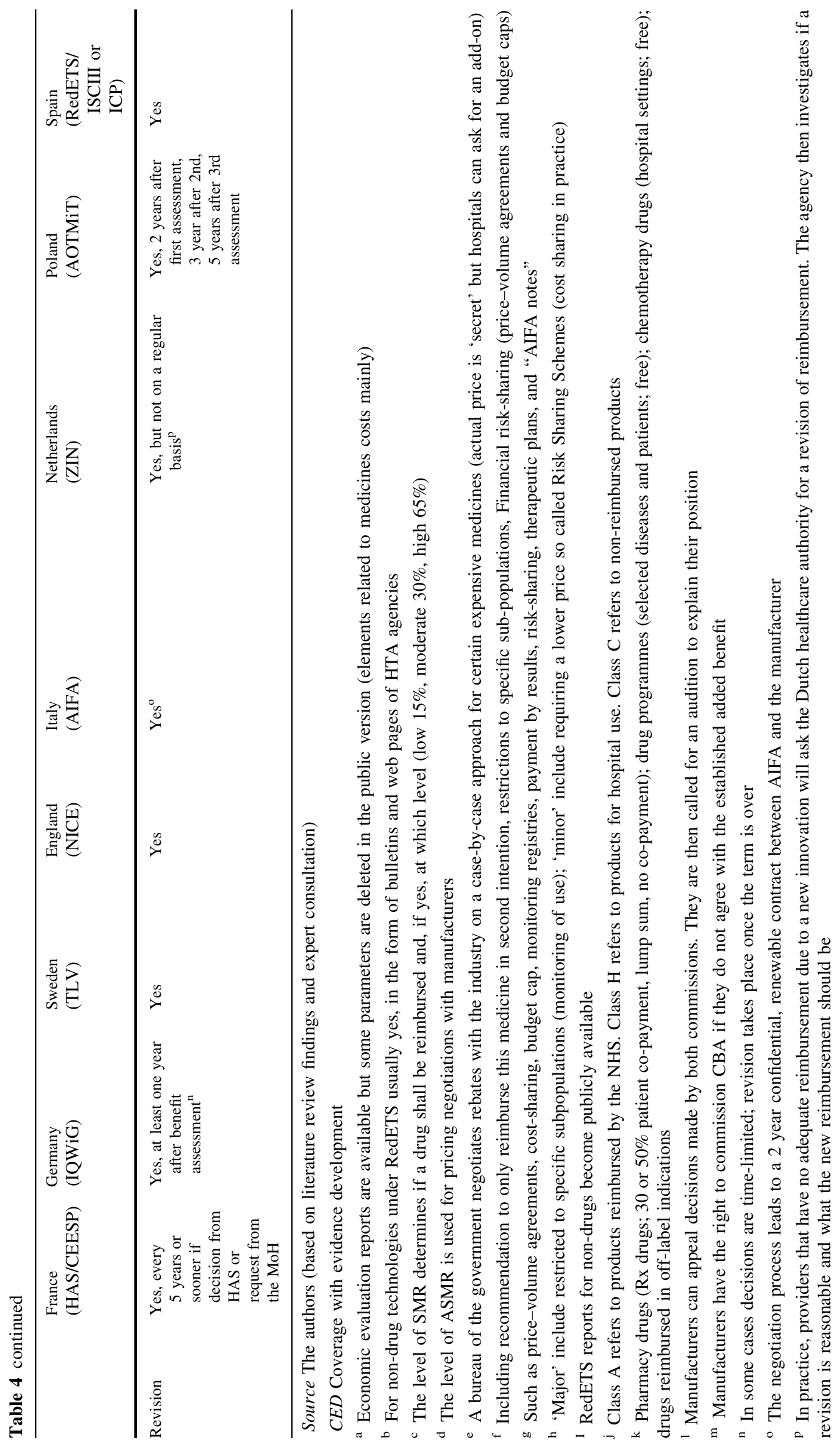




\section{Access restrictions}

All countries apply access restrictions, usually relating to specific indications or specific population sub-groups. France mainly uses financial risk-sharing (price-volume) agreements [56]. Sweden issues temporary decisions for cases when there is insufficient certainty around the (clinical) evidence [56], and risk sharing agreements may take place to speed up the reimbursement process upon the requirement of additional evidence following the review [31], in addition to restricting access for specific sub-populations. In England, major and minor restrictions exist: the former relate to cases where the technology is indicated only for second-line treatment (and beyond), or only for specific sub-populations, and the latter relate to the need for specialist supervision or treatment monitoring [39]; performance based agreements (also known as patient access schemes) also exist, especially in regards to the use of biologics and cancer drugs, according to which a prespecified clinical (endpoint) condition must be reached at a specific post-assessment time point, i.e. response rules, for the coverage of the technology to continue [88]. The inclusion of expensive cancer drugs which are deemed cost-ineffective in the cancer drugs fund (CDF) is indicative of efforts to enable access to very costly medicines to patients that need them on a selective basis.

In the Netherlands, the system of coverage with evidence development (CED) for high cost and orphan inpatient drugs was used extensively between 2006 and 2011 . Currently, financial-based agreements and performancebased risk sharing agreements are considered as well. In Poland, restrictions could be applied to a positive recommendation, which can be either major, e.g. restricted to specific subpopulations (monitoring of use), or minor, e.g. requiring a lower price (so called Risk Sharing Schemes, but cost sharing in practice) [25]. In Spain, MEAs are concluded at the regional level. Price volume agreements (PVAs) are usually applied to single new products where the negotiated price is conditional on the expected number of units sold.

\section{Dissemination and implementation}

Most countries employ dissemination procedures in order to support the implementation of their decisions, including prescribing guidelines and national drug formularies [43]. In France, since 2013, there is a public online drug database allowing the general public to access data and documents on marketed drugs [89]. In Germany, IQWiG prepares a variety of dissemination products besides the dossier assessment including technical scientific reports (and rapid reports where no commenting procedures take place), but also public and user-friendly health information and working papers on recent developments in the field, including methodological aspects [52]. The dossier assessment is provided by the G-BA, which can also issue prescribing advice [25]. In Sweden, at least for the review of products that are already on the positive list, informational material in the form of a fact sheet is produced (possibly accompanied by supplementary information taking the form of a PowerPoint presentation and an FAQ sheet), covering the analysis, the appraisal and the conclusion of the evaluation, distributed to the major stakeholders on the date of the decision and about a week before it becomes publicly available online [35, 36]. In England, the NHS is legally obliged to implement NICE guidance and fund the recommended technologies within 3 months of the outcome of the decision [53, 60]. In Poland, since the Reimbursement Act (issued in 2011, effective from 1 January 2012), drugs can be reimbursed under different lists [25]. Pharmacy reimbursement includes prescribedonly medicines available to patients through four main categories of co-payment. Chemotherapy drugs are available in hospital settings free of charge. Other "regimen" programs are available, under which drugs for selected diseases are reimbursed fully to strictly defined patient populations whose eligibility is decided by appropriate clinician committees.

\section{Appeal mechanisms and review of decisions}

Most countries have appeal mechanisms in place in case of dissent and they all revise their decisions either according to fixed time schedule or on a rolling basis [56, 61]; in France, the drug registration is subject to renewal every five years and a drug may also be subject to post-registration studies. Sweden re-evaluates its old reimbursement list and both Sweden and England may revise technologies once new evidence becomes available. On average, positive recommendations (with or without restrictions) account for approximately 90\% of NICE's appraisals [90].

Although it appears that revisions were taking place systematically after four years for in-patient drugs and on an ad hoc basis for out-patient drugs [42, 56], more recent evidence suggests that, in practice, the process is irregular and providers that have no adequate reimbursement due to a new innovation will ask the Dutch healthcare authority for a revision of reimbursement. The agency then investigates if a revision is reasonable and what the new reimbursement should be [25]. In Italy, the negotiation process leads to a 2 -year, confidential, renewable contract between AIFA and the manufacturer [25]; a possible revision is feasible on the grounds of a new product exceeding the original forecast of a company. 


\section{Discussion}

In all study countries, HTA agencies have an autonomous function. The evaluation process of medical technologies typically involves an initial assessment of evidence conducted by technical groups, followed by the appraisal of the assessed evidence from an expert committee that is producing reimbursement and coverage recommendation(s) for the final decision body, which can be either the payer (e.g. MoH, HIF), or the HTA agency itself.

In addition to the comparative assessment of clinical benefit, most countries implement a type of economic evaluation (mainly CUA or CEA) as the main analytical method to determine the value of new technologies, with the preferred health gain measure usually being the QALY, or alternative patient-relevant (if not final) outcomes. Both direct preference-based elicitation techniques (e.g. TTO, $\mathrm{SG}$ ) and indirect multi-attribute classification systems (e.g. EQ-5D and HUI3) are used to elicit utility scores either from patients or the general population. The debate around preferred health gain measures is strong and often contradictory across jurisdictions. For example, while NICE in England favours the use of the QALY, IQWiG in Germany strongly opposes its use on the grounds that it does not reflect patient-level utilities being the ones that actually matter, rather than population-based utilities [25].

The evaluation (assessment and appraisal) outcome is used mainly as an aid to make coverage recommendations in relation to the reimbursement status of medical technologies, but the analysis outcomes are also used to influence pricing decisions as well (although this is done only indirectly in England). Access restrictions for sub-populations or sub-indications, possibly through the application of risk-sharing agreements, have become common practice across many jurisdictions. Information material is often disseminated by the HTA agencies to a range of stakeholder groups; the implementation of agencies' recommendations is usually taking the form of prescribing guidelines and inclusion into drug formularies. Technology suppliers across all jurisdictions have the option of dissent/ appeal and revision of recommendations is taking place either over a standard period of time or when new evidence becomes available.

Our results show that additional value concerns going beyond economic evaluation or clinical benefit assessment are captured to a different extent or included in the evaluation process as criteria that may help to explain some of the heterogeneity observed in coverage recommendations and decision-making.

Overall, all countries assess similar types of evidence; however, the specific endpoints used, their level of provision and requirement, the way they are incorporated (e.g. explicitly vs. implicitly) and their relative importance vary across countries. The same holds for the interpretation of the submitted evidence by HTA agencies [7]. Overall, the main evidence assessed could be divided into six clusters of information: (1) burden of disease, (2) therapeutic and safety impact, (3) innovation level, (4) socioeconomic impact, (5) efficiency considerations, and (6) other sources of evidence and criteria.

\section{Conceptual and methodological limitations in value assessment}

Current value assessment (VA) approaches mainly consider comparative clinical efficacy in combination with clinical cost-effectiveness techniques, while increasingly incorporating real world data after a new drug has entered the market, thus essentially reflecting comparative effectiveness and efficiency. However, there is considerable subjectivity in the criteria selection used to interpret evidence and determine product value, notably which metrics can be used to measure efficacy and effectiveness, what type of costs need to be considered, and, very importantly, how to account for other key dimensions of value.

Most VA approaches examine the efficacy/effectiveness, or cost-effectiveness of new interventions by mostly addressing only a partial dimension of 'overall value' in a systematic and explicit manner that relates mainly to 'scientific value judgments' ( $\mathrm{ScVJ}$ ) of their therapeutic aspect (e.g. safety, efficacy, effectiveness), possibly in relation to cost. However, as many HTA agencies have recognised (at least indirectly), the value of new medical technologies is multi-dimensional, and not only limited to clinical benefit and cost. In addition to commonly used ScVJ, which are based solely on "scientific" evidence relating to clinical cost-effectiveness and ICERs, other "social" value factors (social value judgements-SoVJ), falling under the information clusters of burden of disease, innovation level and socioeconomic impact, also play a definitive role in the deliberative process and, ultimately, in decision-making; however, there is little, if any, evidence on how SoVJ are captured formally in the appraisal process across settings.

In most settings, the absence of clarity on the use of SoVJ, including their interplay with ScVJ, and their influence on coverage recommendations, remains unknown. SoVJs are usually considered implicitly by HTAs or decision-makers mostly on an ad-hoc basis. In most cases it is not known what their relative importance is, and what tradeoffs HTA agencies are willing to make. As a result, the concept of 'overall value' remains elusive, given that multiple evaluation criteria apply across different settings, with differential intensity and in a non-systematic manner. 


\section{Policy implications and ways forward}

Following the technical review of policy initiatives and opportunities for collaboration and research for access to new medicines in Europe, WHO proposes far more extensive use of HTA in decision-making [91]. However, for this to take place, a more holistic perspective and coordinated action would be needed.

Decision-makers, as well as other stakeholders, need clear, comprehensive and transparent ways of assessing clinical and economic benefit and the impact those new treatments have, from a wider socio-economic perspective, in order to make rational decisions about priority setting. Not having such methods creates a conceptual, methodological and policy gap. Appropriate adaptations of current methodologies, or development of new transparent conceptual frameworks, seem to be needed.

NICE in England is one of the forerunner agencies in acknowledging, formalising and creating a methodological landscape for SoVJ, which include, first, the burden of disease the treatment addresses, hence the clinical and policy importance of the health topic under consideration; second, the cost impact on resources from a societal perspective; third, policy objectives relating to the long-term benefits of innovation [92-94], and, in general, the broader balance between benefits and costs. The existing influence of disease severity could be illustrated in the context of EoL treatments, where QALYs gained for terminal illnesses have a greater weight [95], on the grounds that society places a special value on extending the lives of the terminally ill [96]. Decision makers have been exploring new ways of considering additional value parameters, while highlighting the need for "a broader and more transparent assessment" methodology, suggesting a move towards value-based assessment [97, 98]. A comparable approach highlighting the broader societal implications of introducing a new technology, addressing considerations of need, equity and human dignity, are also present explicitly in the case of the Swedish TLV. Despite the explicit nature of these broader considerations, it is unclear what their influence is in shaping VAs and coverage recommendations.

Aspects of HTA shortcomings have also been reflected by various recent initiatives seeking to establish "value frameworks" aiming to aid pricing and clinical practice decisions by considering a variety of parameters for the assessment of value, possibly in relation to costs. Most of that work has been led by professional associations seeking clarity on the determinants of value and their relative importance to different stakeholders [99-103]. However, attention should be paid to their methodologies, for recommendations to be robust and to avoid misguided decisions [104]. All these initiatives have attempted to adopt multicriteria evaluation approaches, albeit in a very simplified and relatively abstract manner. Other approaches embedded in decision analysis could address benefit-risk assessment considerations of health care interventions [105, 106]. Considering the limitations highlighted by this systematic review in the context of HTA as it is practised currently, it looks as though multi-criteria decision analysis methods could be explored to capture the value of new medical technologies in a holistic manner and, through this, facilitate HTA decision-making processes in a spirit of transparency, comprehensiveness, and flexibility [107, 108].

The heterogeneity in VA systems across Europe, which also results in significant difference in coverage recommendations across settings based on how HTA agencies perceive or interpret evidence and the associated uncertainties, has recently acquired another important dimension; in September 2016, the European Commission outlined its thoughts to strengthen EU cooperation on HTA [109]. The Commission's vision includes several options, ranging from voluntary long-term cooperation to cooperation on the production of full joint HTA reports. While it is very premature to speculate what the likely outcome of this initiative is going to be beyond 2020, when the current Joint Action 3 ends, the Commission's desired course of action seems to be in favour of greater collaboration amongst HTA agencies. Whatever the form of collaboration, member states will undoubtedly contend that the principle of subsidiarity will need to hold. This implies that member states will continue to exercise control on appraisals and coverage recommendations, but assessment could be done through some form of collaborative arrangement (jointly, via mutual recognition, or otherwise). If so, the precise criteria that are acceptable across member states will need to be clarified and explicitly incorporated into the assessment process. The current heterogeneity in coverage recommendations, which results partly from differences in methods applied in the assessment phase, and special considerations/social value judgements applied in the appraisal phase, may need to be addressed by recognising the relative importance of the latter in the assessment phase. This would provide greater steering to member states during the appraisal phase when they seek to make final decisions on coverage. It will also require significant debate in order to come to a joint understanding on the different criteria and their relative importance that can be used in and inform the assessment phase beyond costs and effects.

\section{Conclusion}

The study highlights a number of significant similarities but also considerable differences in the practices, processes and policies of VA for new medicines across eight study 
countries in Europe. These differences exist because of different national priorities between countries, but also because of different processes and methodological frameworks adopted for the elicitation of decision-makers' preferences. Overall, there is considerable ambiguity with regards to what additional value criteria to incorporate, how to establish their relative importance, and whose preferences to consider. Currently, all these decisions are subject to decision-makers' discretion, but are in most cases exemplified in a less than transparent way, potentially resulting in some form of bias.

Procedures characterized by greater transparency or clarity in terms of value criteria used and a higher degree of comprehensiveness and methodological robustness could lead to more rational evidence-based decision making, contributing to more efficient resource allocation and, potentially, higher societal welfare, while also raising public confidence and fairness in terms of homogeneity and consistency of decision outcomes.

The limitations of the current VA methodologies and the identified conceptual and policy gaps suggest that there is a need for methodological approaches that encompass multiple evaluation criteria explicitly, so that value can be an explicit function of a number of dimensions beyond those that are currently explicitly and sytematically captured. This is increasingly becoming imperative in the context of European collaboration, particularly if some form of joint assessment at EU level is likely to emerge beyond 2020. Decision analysis and multi-criteria evaluation approaches could potentially provide the foundation for measuring and eliciting the value of new medicines and technologies as they provide a comprehensive alternative for quantitative modelling.

Acknowledgements This study has been prepared under the auspices of Advance-HTA, a research project that has received funding from the European Commission, DG Research (Grant Agreement No: 305983). The views represented in the study are those of the authors and do not necessarily reflect the views of the European Commission.

We are grateful to the following experts for reviewing the results tables and providing useful feedback: Karl Arnberg, Karen Brigham, Agnese Cangini, Guillaume Dedet, Jaime Espin, Mathilde Grande, Kinga Grzywacz, Patrick Jeurissen, Douglas Lundin, Armando Magrelli, Dimitra Panteli, Dominique Polton, Pierluigi Russo, Annalisa Sammarco, Pedro Serrano, Giovanni Tafuri, Beate Wieseler, Julian Witte and Anna Zawada. We are thankful to Alistair McGuire for comments and suggestions to earlier versions of the paper and to Victoria Tzouma and Erica Visintin for valuable research assistance. Finally, we are thankful to the partners of the AdvanceHTA consortium for helpful comments and suggestions in earlier versions of the paper. All remaining errors are our own.

Open Access This article is distributed under the terms of the Creative Commons Attribution 4.0 International License (http:// creativecommons.org/licenses/by/4.0/), which permits unrestricted use, distribution, and reproduction in any medium, provided you give appropriate credit to the original author(s) and the source, provide a link to the Creative Commons license, and indicate if changes were made.

\section{References}

1. Weinstein, M.C., Torrance, G., McGuire, A.: QALYs: the basics. Value Health 12(Supplement s1), s5-s9 (2009)

2. Brouwer, W., Van Exel, J., Baker, R., Donaldson, C.: The new myth. PharmacoEconomics 26(1), 1-4 (2008)

3. Wouters, O.J., Naci, H., Samani, N.J.: QALYs in cost-effectiveness analysis: an overview for cardiologists. Heart (British Cardiac Society) 101(23), 1868-1873 (2015). doi:10.1136/ heartjnl-2015-308255

4. Goldman, D., Lakdawalla, D., Philipson, T.J., Yin, W.: Valuing health technologies at nice: recommendations for improved incorporation of treatment value in HTA. Health Econ. 19(10), 1109-1116 (2010). doi:10.1002/hec.1654

5. Runge, C.: Separating the wheat from the chaff. Eur. J. Health Econ. 13, 121 (2012). doi:10.1007/s10198-011-0375-2

6. Sussex, J., Towse, A., Devlin, N.: Operationalizing value-based pricing of medicines. PharmacoEconomics 31(1), 1-10 (2013). doi:10.1007/s40273-012-0001-x

7. Nicod, E., Kanavos, P.: Developing an evidence-based methodological framework to systematically compare HTA coverage decisions: a mixed methods study. Health Policy 120(1), 35-45 (2016). doi:10.1016/j.healthpol.2015.11.007

8. Anell, A.: Priority setting for pharmaceuticals. The use of health economic evidence by reimbursement and clinical guidance committees. Eur. J. Health Econ. 5(1), 28-35 (2004)

9. Banta, D.: The development of health technology assessment. Health Policy 63(2), 121 (2003)

10. Gregoire, J., MacNeil, P., Skilton, K., Moisan, J., Menon, D., Jacobs, P., et al.: Inter-provincial variation in government drug formularies. Can. J. Public Health 92, 307-312 (2001)

11. Kanavos, P., Nicod, E., van der Aardweg, S., Pomedli, S.: The impact of health technology assessments: an international comparison. Health Policy Bull. Eur. Obs. Health Syst. Policies 12(4) (2010)

12. Morgan, S.G., McMahon, M., Mitton, C., Roughead, E., Kirk, R., Kanavos, P., Menon, D.: Centralized drug review processes in Australia, Canada, New Zealand, and the United Kingdom. Health Aff. (Project Hope) 25(2), 337-347 (2006)

13. Nicod, E., Kanavos, P.: Commonalities and differences in HTA outcomes: a comparative analysis of five countries and implications for coverage decisions. Health Policy 108(2/3), 167-177 (2012). doi:10.1016/j.healthpol.2012.09.012

14. Schwarzer, R., Siebert, U.: Methods, procedures, and contextual characteristics of health technology assessment and health policy decision making: comparison of health technology assessment agencies in Germany, United Kingdom, France, and Sweden. Int. J. Technol. Assess. Health Care 25(3), 305-314 (2009). doi:10.1017/S0266462309990092

15. Dionne, F., Mitton, C., Smith, N., Donaldson, C.: Decision maker views on priority setting in the Vancouver Island Health Authority. Cost Eff. Resour. Alloc. 6, 13 (2008). doi:10.1186/ 1478-7547-6-13

16. Mitton, C.R., McMahon, M., Morgan, S., Gibson, J.: Centralized drug review processes: are they fair? Soc. Sci. Med. (1982) 63(1), 200-211 (2006)

17. Teng, F., Mitton, C., Mackenzie, J.: Priority setting in the provincial health services authority: survey of key decision makers. BMC Health Serv. Res. 7, 84 (2007)

18. Daniels, N.: Decisions about access to health care and accountability for reasonableness. J. Urban Health 76(2), 176-191 (1999)

19. Kanavos, P.: The future of health technology assessment: evidence from Europe and the Americas and an agenda for policy action. European Observatory, Brussels (2016). 
20. Advance-HTA.: Advance-HTA webpage. http://www.advancehta.eu/ (2013). Accessed June 2016

21. Hutton, J., McGrath, C., Frybourg, J.-M., Tremblay, M., Bramley-Harker, E., Henshall, C.: Framework for describing and classifying decision- making systems using technology assessment to determine the reimbursement of health technologies (fourth hurdle systems). Int. J. Technol. Assess. Health Care 22(1), 10-18 (2006). doi:10.1017/S0266462306050781

22. Rogowski, W.H., Hartz, S.C., John, J.H.: Clearing up the hazy road from bench to bedside: a framework for integrating the fourth hurdle into translational medicine. BMC Health Serv. Res. 8, 194 (2008). doi:10.1186/1472-6963-8-194

23. Fischer, K.E.: Decision-making in healthcare: a practical application of partial least square path modelling to coverage of newborn screening programmes. BMC Med. Inform. Decis. Mak. 12, 83 (2012). doi:10.1186/1472-6947-12-83

24. Centre for Reviews and Dissemination.: Systematic reviews: CRD's guidance for undertaking reviews in health care. University of York. https://www.york.ac.uk/media/crd/Systema tic_Reviews.pdf (2009). Accessed 21 June 2016

25. Advance-HTA.: Personal communication with experts. Advance-HTA Project (2016)

26. McGhan, W.F., Al, M., Doshi, J.A., Kamae, I., Marx, S.E., Rindress, D.: The ISPOR good practices for quality improvement of cost-effectiveness research task force report. Value Health 12(8), 1086-1099 (2009). doi:10.1111/j.1524-4733.2009.00605.x

27. ISPOR.: Pharmacoeconomic Guidelines Around The WorldPharmacoeconomic guidelines around the world. http:// www.ispor.org/peguidelines/index.asp (2014). Accessed 22 June 2016

28. Mauskopf, J., Walter, J., Birt, J., Bowman, L., Copley-Merriman, C., Drummond, M.: Differences among formulary submission guidelines: implications for health technology assessment. Int. J. Technol. Assess. Health Care 27(3), 261-270 (2011). doi:10.1017/S0266462311000274

29. Toumi, M., Rémuzat, C., El Hammi, E., Millier, A., Aballéa, S., Chouaid, C., Falissard, B.: Current process and future path for health economic assessment of pharmaceuticals in France. J. Mark. Access Health Policy 3 (2015). doi:10.3402/jmahp.v3. 27902

30. G-BA.: Chapter 5: benefit Assessment of pharmaceuticals according to s. 35a SGB V. Gemeinsame Bundesausschuss. http://www.english.g-ba.de/downloads/17-98-3042/Chapter5Rules-of-Procedure-G-BA.pdf (2015). Accessed 23 June 2016

31. Persson, U., Willis, M., Ödegaard, K.: A case study of ex ante, value- based price and reimbursement decision-making: TLV and rimonabant in Sweden. Eur. J. Health Econ. 11(2), 195-203 (2010). doi:10.1007/s10198-009-0166-1

32. Drummond, M., Jönsson, B., Rutten, F., Stargardt, T.: Reimbursement of pharmaceuticals: reference pricing versus health technology assessment. Eur. J. Health Econ. 12(3), 263-271 (2011). doi:10.1007/s10198-010-0274-y

33. Kenny, N., Joffres, C.: An ethical analysis of international health priority-setting. Health Care Anal. 16(2), 145-160 (2008). doi:10.1007/s10728-007-0065-5

34. Calltorp, J.: Priority setting in health policy in Sweden and a comparison with Norway. Health Policy (Amsterdam, Netherlands) 50(1-2), 1-22 (1999)

35. TLV.: Guide for companies when applying for subsidies and pricing for pharmaceutical products. The Dental and Pharmaceutical Benefits Agency. http://www.tlv.se/Upload/English/ ENG-guide-for-companies.pdf (2012). Accessed 22 June 2016

36. TLV.: Handbook-reviewing the reimbursement status of pharmaceuticals. The Dental and Pharmaceutical Benefits Agency. http://www.tlv.se/Upload/English/ENG-handbook.pdf (2012). Accessed 22 June 2016
37. NICE.: SOCIAL VALUE JUDGEMENTS: principles for the development of NICE guidance. National Institute for Health and Care Excellence. https://www.nice.org.uk/media/default/ about/what-we-do/research-and-development/social-value-judge ments-principles-for-the-development-of-nice-guidance.pdf (2008). Accessed 23 June 2016

38. Buxton, M.: Implications of the appraisal function of the National Institute for Clinical Excellence (NICE). Value Health 4(3), 212-216 (2001)

39. Jena, A.B., Philipson, T.J.: Endogenous cost-effectiveness analysis and health care technology adoption. J. Health Econ. 32(1), 172-180 (2013). doi:10.1016/j.jhealeco.2012.10.002

40. Rawlins, M., Culyer, A.: National institute for clinical excellence and its value judgments. Br. Med. J. 329(7459), 224-227 (2004)

41. Golan, O., Hansen, P., Kaplan, G., Tal, O.: Health technology prioritization: which criteria for prioritizing new technologies and what are their relative weights? Health Policy 102(2), 126-135 (2011). doi:10.1016/j.healthpol.2010.10.012

42. Cleemput, I., Franken, M., Koopmanschap, M., le Polain, M.: European drug reimbursement systems' legitimacy: five-country comparison and policy tool. Int. J. Technol. Assess. Health Care 28(4), 358-366 (2012). doi:10.1017/S0266462312000529

43. Franken, M., Nilsson, F., Sandmann, F., Boer, A., Koopmanschap, M.: Unravelling drug reimbursement outcomes: a comparative study of the role of pharmacoeconomic evidence in Dutch and Swedish reimbursement decision making. PharmacoEconomics 31(9), 781-797 (2013). doi:10.1007/s40273-0130074-1

44. Banta, D., de Wit, A.: Public health services and cost-effectiveness analysis. Annu. Rev. Public Health 29, 383-397 (2008). doi:10.1146/annurev.publhealth.29.020907.090808

45. Dirksen, C.D., Utens, C.M., Joore, M.A., van Barneveld, T.A., Boer, B., Dreesens, D.H., van Laarhoven, H., Smit, C., Stiggelbout, A.M., van der Weijden, T.: Integrating evidence on patient preferences in healthcare policy decisions: protocol of the patient-VIP study. Implement. Sci. 8, 64 (2013). doi:10. 1186/1748-5908-8-64

46. Banta, D., Oortwijn, W.J.: The Netherlands. Int. J. Technol. Assess. Health Care 25(Suppl 1), 143-147 (2009). doi:10.1017/ S0266462309090564

47. Mapelli, V., Lucioni, C.: Spending on pharmaceuticals in Italy: macro constraints with local autonomy. Value Health 6(Suppl 1), S31-S45 (2003)

48. Niżankowski, R., Wilk, N.: From idealistic rookies to a regional leader: the history of health technology assessment in Poland. Int. J. Technol. Assess. Health Care 25(S1), 156-162 (2009). doi: $10.1017 /$ S0266462309090588

49. Antoñanzas, F.: Challenges to achieving value in drug spending in a decentralized country: the spanish case. Value Health $\mathbf{6}$, S52-S63 (2003). doi:10.1046/j.1524-4733.6.s1.6.x

50. HAS.: Choices in methods for economic evaluation. Haute Autorité de santé. http://www.has-sante.fr/portail/upload/docs/ application/pdf/2012-10/choices_in_methods_for_economic_ evaluation.pdf (2012). Accessed 22 June 2016

51. HAS.: La Commission évaluation économique et de santé publique (CEESP). Haute Autorité de Santé. http://www.hassante.fr/portail/upload/docs/application/pdf/2012-11/quest-ce_ que_la_ceesp-brochure2clics_2012-11-22_10-13-34_631.pdf (2012). Accessed 23 June 2016

52. IQWiG.: General methods. Institute for Quality and Efficiency in Health Care, Cologne (2011)

53. Trowman, R., Chung, H., Longson, C., Littlejohns, P., Clark, P.: The National Institute for Health and Clinical Excellence and its role in assessing the value of new cancer treatments in England and Wales. Clin. Cancer Res. 17(15), 4930-4935 (2011). doi:10. 1158/1078-0432.CCR-10-2510 
54. Hughes-Wilson, W., Palma, A., Schuurman, A., Simoens, S.: Paying for the orphan drug system: break or bend? Is it time for a new evaluation system for payers in Europe to take account of new rare disease treatments? Orphanet J. Rare Dis. 7, 74 (2012). doi:10.1186/1750-1172-7-74

55. Kaltenthaler, E., Boland, A., Carroll, C., Dickson, R., Fitzgerald, P., Papaioannou, D.: Evidence review group approaches to the critical appraisal of manufacturer submissions for the NICE STA process: a mapping study and thematic analysis. Health Technol. Assess. (Winchester, England) 15(22), 1 (2011). doi:10.3310/hta15220

56. Franken, M., le Polain, M., Cleemput, I., Koopmanschap, M.: Similarities and differences between five European drug reimbursement systems. Int. J. Technol. Assess. Health Care 28(4), 349-357 (2012). doi:10.1017/S0266462312000530

57. Kleijnen, S., George, E., Goulden, S., d'Andon, A., Vitré, P., Osińska, B., Rdzany, R., Thirstrup, S., Corbacho, B., Nagy, B.Z., Leufkens, H.G., de Boer, A., Goettsch, W.G.: Relative effectiveness assessment of pharmaceuticals: similarities and differences in 29 jurisdictions. Value Health 15(6), 954-960 (2012). doi:10.1016/j.jval.2012.04.010

58. Schubert, F.: Health technology assessment. The pharmaceutical industry perspective. Int. J. Technol. Assess. Health Care 18(2), 184-191 (2002)

59. Towse, A., Pritchard, C.: National Institute for Clinical Excellence (NICE): is economic appraisal working? PharmacoEconomics 20(15), 95-105 (2002)

60. Clement, F.M., Harris, A., Li, J.J., Yong, K., Lee, K.M., Manns, B.J.: Using effectiveness and cost-effectiveness to make drug coverage decisions: a comparison of Britain, Australia, and Canada. JAMA 302(13), 1437-1443 (2009). doi:10.1001/jama. 2009.1409

61. Zentner, A., Velasco-Garrido, M., Busse, R.: Methods for the comparative evaluation of pharmaceuticals. GMS Health Technol. Assess. 1, Doc09 (2005)

62. Le Pen, C., Priol, G., Lilliu, H.: What criteria for pharmaceuticals reimbursement? An empirical analysis of the evaluation of "medical service rendered" by reimbursable drugs in France. Eur. J. Health Econ. 4(1), 30-36 (2003)

63. IQWiG.: General methods. Institut für Qualität und Wirtschaftlichkeit im Gesundheitswesen. https://www.iqwig.de/down load/IQWiG_General_Methods_Version_\%204-2.pdf (2015). Accessed 23 June 2016

64. Gridchyna, I., Aulois-Griot, M., Maurain, C., Bégaud, B.: How innovative are pharmaceutical innovations?: the case of medicines financed through add-on payments outside of the French DRG-based hospital payment system. Health Policy (Amsterdam, Netherlands) 104(1), 69-75 (2012). doi:10.1016/j. healthpol.2011.11.007

65. IQWiG.: General methods for the assessment of the relation of benefits to costs. Institute for Quality and Efficiency in Health Care. http://www.ispor.org/peguidelines/source/Germany_Assess mentoftheRelationofBenefitstoCosts_En.pdf (2009). Accessed 22 June 2016

66. NICE.: Guide to the methods of technology appraisal 2013. National Institute for Health and Care Excellence. https://www. nice.org.uk/article/pmg9/resources/non-guidance-guide-to-themethods-of-technology-appraisal-2013-pdf (2013). Accessed 21 May 2015

67. Mauskopf, J.A., Sullivan, S.D., Annemans, L., Caro, J., Mullins, C.D., Nuijten, M., Orlewska, E., Watkins, J., Trueman, P.: Principles of good practice for budget impact analysis: report of the ISPOR Task Force on good research practices-budget impact analysis. Value Health 10(5), 336-347 (2007)

68. Manchikanti, L., Falco, F.J.E., Boswell, M.V., Hirsch, J.A.: Facts, fallacies, and politics of comparative effectiveness research: part 2-implications for interventional pain management. Pain Physician 13(1), E55-E79 (2010)

69. Milne, R., Clegg, A., Stevens, A.: HTA responses and the classic HTA report. J. Public Health Med. 25(2), 102-106 (2003)

70. Dakin, H.A., Devlin, N.J., Odeyemi, I.A.O.: "Yes", "No" or "Yes, but"? Multinomial modelling of NICE decision-making. Health Policy 77(3), 352-367 (2006). doi:10.1016/j.healthpol. 2005.08.008

71. Boersma, C., Broere, A., Postma, M.J.: Quantification of the potential impact of cost-effectiveness thresholds on dutch drug expenditures using retrospective analysis. Value Health 13(6), 853-856 (2010). doi:10.1111/j.1524-4733.2010.00736.x

72. Devlin, N., Parkin, D.: Does NICE have a cost-effectiveness threshold and what other factors influence its decisions? A binary choice analysis. Health Econ. 13(5), 437-452 (2004)

73. Corbacho, B., Pinto-Prades, J.L.: Health economic decisionmaking: a comparison between UK and Spain. Br. Med. Bull. 103(1), 5-20 (2012). doi:10.1093/bmb/lds017

74. von der Schulenburg, J.M.G., Vauth, C., Mittendorf, T., Greiner, W.: Methods for determining cost-benefit ratios for pharmaceuticals in Germany. Eur. J. Health Econ. 8(Suppl 1), S5-S31 (2007)

75. Kirkdale, R., Krell, J., Hanlon Brown, C., Tuthill, M., Waxman, J.: The cost of a QALY. QJM 103(9), 715-720 (2010). doi:10. 1093/qjmed/hcq081

76. Sjögren, E.: Deciding subsidy for pharmaceuticals based on ambiguous evidence. J. Health Organ. Manag. 22(4), 368-383 (2008)

77. McMahon, M., Morgan, S., Mitton, C.: The common drug review: a NICE start for Canada? Health Policy 77(3), 339-351 (2006). doi:10.1016/j.healthpol.2005.08.006

78. CVZ.: Guidelines for pharmacoeconomic research, updated version. College voor Zorgverzekeringen, Diemen, The Netherlands (2006)

79. Capri, S., Ceci, A., Terranova, L., Merlo, F., Mantovani, L.: Guidelines for economic evaluations in Italy: recommendations from the Italian Group of Pharmacoeconomic Studies. Drug Inf. J. 35, 189-201 (2001)

80. Hoyle, M.: Historical lifetimes of drugs in England: application to value of information and cost-effectiveness analyses. Value Health 13(8), 885-892 (2010). doi:10.1111/j.1524-4733.2010.00778.x

81. Ozieranski, P., McKee, M., King, L.: The politics of health technology assessment in Poland. Health Policy 108(2-3), 178-193 (2012). doi:10.1016/j.healthpol.2012.10.001

82. Raftery, J.: Review of NICE'S recommendations, 1999-2005. Br. Med. J. 332(7552), 1266-1268 (2006)

83. Simoens, S.: Use of economic evaluation in decision making: evidence and recommendations for improvement. Drugs 70(15), 1917-1926 (2010). doi:10.2165/11538120-000000000-00000

84. NICE.: The guidelines manual. National Institute for Health and Clinical Excellence, London (2009)

85. Stewart, A., Aubrey, P., Belsey, J.: Addressing the health technology assessment of biosimilar pharmaceuticals. Curr. Med. Res. Opin. 26(9), 2119-2126 (2010). doi:10.1185/03007995.2010. 505137

86. Claxton, K., Martin, S., Soares, M., Rice, N., Spackman, E., Hinde, S., Devlin, N., Smith, P.C., Sculpher, M.: Methods for the estimation of the National Institute for Health and Care Excellence cost-effectiveness threshold. Health Technol. Assess. 19(14), 1-503, v-vi (2015). doi:10.3310/hta19140

87. Svensson, M., Nilsson, F.O., Arnberg, K.: Reimbursement decisions for pharmaceuticals in Sweden: the impact of disease severity and cost effectiveness. Pharmacoeconomics 33(11), 1229-1236 (2015). doi:10.1007/s40273-015-0307-6

88. Briggs, A.H., Levy, A.R.: Pharmacoeconomics and Pharmacoepidemiology: curious bedfellows or a match made in heaven? Pharmacoeconomics 24, 1079-1086 (2006) 
89. HAS.: Évaluation médico-économique des produits de santé. http://www.has-sante.fr/portail/jcms/r_1502595/fr/evaluationmedico-economique-des-produits-de-sante (2013). Accessed June 2016

90. Chalkidou, K.: Evidence and values: paying for end-of-life drugs in the British NHS. Health Econ. Policy Law 7(4), 393-409 (2012). doi:10.1017/S1744133112000205

91. WHO.: Access to new medicines in Europe: technical review of policy initiatives and opportunities for collaboration and research. World Health Organisation Regional Office for Europe. http://apps.who.int/medicinedocs/documents/s21793en/ s21793en.pdf (2015). Accessed 23 June 2016

92. NICE.: Guide to the technology appraisal process. National Institute for Health and Clinical Excellence, London (2004)

93. NICE.: Department of Health Selection Criteria. National Institute for Health and Clinical Excellence, London (2006)

94. Shah, K.K., Cookson, R., Culyer, A.J., Littlejohns, P.: NICE's social value judgements about equity in health and health care. Health Econ. Policy Law 8, 145-165 (2013)

95. Longson, C., Littlejohns, P.: Update report on the application of the 'end-of-life' supplementary advice in health technology appraisals. NICE, London (2009)

96. Rawlins, M., Barnett, D., Stevens, A.: Pharmacoeconomics: NICE's approach to decision making. Br. J. Clin. Pharmacol. 70(3), 346-349 (2010)

97. Department of Health: A new value-based approach to the pricing of branded medicines: a consultation (2010). Availaable at: http://webarchive.nationalarchives.gov.uk/20130107105354/ http:/www.dh.gov.uk/prod_consum_dh/groups/dh_digitalassets/ @ dh/@en/documents/digitalasset/dh_122793.pdf

98. Department of Health: A new value-based approach to the pricing of branded medicines: government response to consultation (2011). Available at: http://static.correofarmaceutico.com/ docs/2011/07/ru_consulta_publica.pdf

99. Schnipper, L.E., Davidson, N.E., Wollins, D.S., Tyne, C., Blayney, D.W., Blum, D., Dicker, A.P., Ganz, P.A., Hoverman, J.R., Langdon, R., Lyman, G.H., Meropol, N.J., Mulvey, T., Newcomer, L., Peppercorn, J., Polite, B., Raghavan, D., Rossi, G., Saltz, L., Schrag, D., Smith, T.J., Yu, P.P., Hudis, C.A., Schilsky, R.L., American Society of Clinical, O: American Society of Clinical Oncology Statement: a conceptual framework to assess the value of cancer treatment options. J. Clin. Oncol. 33(23), 2563-2577 (2015). doi:10.1200/JCO.2015.61. 6706

100. Cherny, N.I., Sullivan, R., Dafni, U., Kerst, J.M., Sobrero, A., Zielinski, C., de Vries, E.G.E., Piccart, M.J.: A standardised, generic, validated approach to stratify the magnitude of clinical benefit that can be anticipated from anti-cancer therapies: the European Society for Medical Oncology Magnitude of Clinical Benefit Scale (ESMO-MCBS). Ann. Oncol. 26(8), 1547-1573 (2015). doi:10.1093/annonc/mdv249

101. Anderson, J.L., Heidenreich, P.A., Barnett, P.G., Creager, M.A., Fonarow, G.C., Gibbons, R.J., Halperin, J.L., Hlatky, M.A., Jacobs, A.K., Mark, D.B., Masoudi, F.A., Peterson, E.D., Shaw, L.J.: ACC/AHA statement on cost/value methodology in clinical practice guidelines and performance measures: a report of the American College of Cardiology/American Heart Association Task Force on Performance Measures and Task Force on Practice Guidelines. J. Am. Coll. Cardiol. 63(21), 2304-2322 (2014). doi:10.1016/j.jacc.2014.03.016

102. Bach, P.: DrugAbacus App. http://app.drugabacus.org/abacusmskcc (2015). Accessed June 2016

103. NCCN.: NCCN Clinical Practice Guidelines in Oncology (NCCN Guidelines ${ }^{\circledR}$ ) with NCCN Evidence Blocks ${ }^{\mathrm{TM}}$. http:// www.nccn.org/evidenceblocks/ (2015). Accessed 23 June 2016

104. Angelis, A., Kanavos, P.: Critique of the American Society of Clinical Oncology value assessment framework for cancer treatments: putting methodologic robustness first. J. Clin. Oncol. 34(24), 2935-2936 (2016)

105. Phillips, L., Fasolo, B., Zafiropoulos, N., Beyer, A.: Is quantitative benefit-risk modelling of drugs desirable or possible? Drug Discov. Today Technol. 8(1), e1-e42 (2011). doi:10.1016/ j.ddtec.2011.03.001

106. Marsh, K., Lanitis, T., Neasham, D., Orfanos, P., Caro, J.: Assessing the value of healthcare interventions using multi-criteria decision analysis: a review of the literature. PharmacoEconomics 32(4), 345-365 (2014). doi:10.1007/s40273-014-0135-0

107. Angelis, A., Kanavos, P.: Value-based assessment of new medical technologies: towards a robust methodological framework for the application of multiple criteria decision analysis in the context of health technology assessment. Pharmacoeconomics 34(5), 435-446 (2016). doi:10.1007/s40273-015-0370-z

108. Thokala, P., Devlin, N., Marsh, K., Baltussen, R., Boysen, M., Kalo, Z., Longrenn, T., Mussen, F., Peacock, S., Watkins, J., Ijzerman, M.: Multiple criteria decision analysis for health care decision making-an introduction: report 1 of the ISPOR MCDA Emerging Good Practices Task Force. Value Health 19(1), 1-13 (2016). doi:10.1016/j.jval.2015.12.003

109. DG SANTE.: Inception Impact Assessment: Strengthening of the EU cooperation on Health Technology Assessment (HTA). European Commission. http://ec.europa.eu/smart-regulation/ roadmaps/docs/2016_sante_144_health_technology_assessments_ en.pdf (2016). Accessed 23 October 2016 